\title{
Bi-specific and tri-specific antibodies- the next big thing in solid tumor therapeutics
}

Karie Runcie ${ }^{1}$, Daniel R. Budman ${ }^{1,2}$, Veena John $n^{1,2}$ and Nagashree Seetharamu ${ }^{1,2^{*}}$ (D)

\begin{abstract}
Antibody-based therapy has revitalized the world of cancer therapeutics since rituximab was first approved for the treatment of Non-Hodgkin's Lymphoma. Monoclonal antibodies against cancer antigens have been successful strategies for only a handful of cancer types due to many reasons including lack of antibody specificity and complex nature of tumor milieu which interfere with antibody efficacy. Polyspecific antibodies are promising class of anti-cancer agents which can be directed at multiple tumor antigens to eradicate tumor cells more precisely and effectively. They may overcome some of these limitations and have already changed treatment landscape for some malignancies such as B cell acute lymphoblastic leukemia. Pre-clinical studies and early phase clinical trials have demonstrated that this approach may be an effective strategy even for solid tumors. This review focuses on the development of bispecific and trispecific antibody therapy for the treatment of solid tumor malignancies and highlights the potential they hold for future therapies to come.

Keywords: Bispecific antibody, Trispecific antibody, Immunotherapy, Solid tumor
\end{abstract}

\section{Background}

Cancer remains the second leading cause of death in the United States, with lung cancer being the leading cause of cancer deaths, followed by breast cancer in women and prostate cancer in men (Siegel 2017). Over the past few decades, new and targeted therapies have contributed to significant improvements in the 5-year relative overall survival rate for all cancers combined, most prominent in hematopoietic and lymphoid malignancies (Siegel 2017). An integral part of this revolution has been development of monoclonal antibodies in the 1970s. Rituximab, a genetically engineered chimeric antibody against the CD 20 antigen found on the surface of B cells, was the first monoclonal antibody approved by the Food and Drug Administration in 1997 for the treatment of Non-Hodgkin's lymphoma (Leget and Czuczman 1998; White et al. 2000). Since then, the use of monoclonal antibodies for cancer therapy has evolved to target different molecules and has expanded treatment options for solid tumors as well as hematologic malignancies. Despite the excellent tolerability profile and

\footnotetext{
* Correspondence: nseetharamu@northwell.edu

${ }^{1}$ Department of Medicine, Hofstra-Northwell School of Medicine, Hempstead, USA

${ }^{2}$ Division of Hematology and Medical Oncology, Hofstra-Northwell School of Medicine, Hempstead, USA
}

efficacy in various cancers, these agents are rarely effective as monotherapies and have several limitations. Activation of alternate molecular pathways, acquired changes in the tumor milieu, and suboptimal engagement of monoclonal antibodies to their targets are just some of the drawbacks (Fousek and Ahmed 2015). Recent innovations based upon improvements in protein engineering have resulted in combining antibodies for synergistic effect (Henricks et al. 2015; Binyamin et al. 2006); development of antibodies with genetically engineered Fc receptors to achieve higher effector functions such as antibody-dependent cytotoxicity (Binyamin et al. 2006); and creation of bi-specific and tri-specific antibodies which are capable of binding to multiple targets (Segal et al. 1999; Mertens et al. 2001). A search of Pub-Med in February 2018 reveals 2744 articles on bi-specific antibodies with 1784 mentioning cancer. In an analogous fashion for tri-specific antibodies, a search noted 37 articles with 25 mentioning cancer.

\section{Historical review}

The concept of using a molecule with more than one binding site to enhance its biological function actually dates back to 1961 when two antigen-binding fragments from different polyclonal sera were combined to form 
bispecific molecules (Nisonoff and Rivers 1961). The techniques of chemical conjugation of two different antigen-specific monoclonal antibodies and fusion of two antibody producing hybridoma cell lines (quadromas) in the 1970s and 1980s took the production of bispecific antibodies to the next level (Staerz et al. 1985; Karpovsky et al. 1984; Perez et al. 1985). Although some of these primitive formats showed appreciable activity against certain malignancies, the vast majority had a dismal therapeutic-risk index. With rapid advances in genetic engineering, the past two decades have seen a dramatic increase in the production of polyspecific antibodies with more than 120 described formats now in clinical use or undergoing evaluation in clinical trials (Spiess et al. 2015). Even though majority of the early development of polyspecific antibodies was focused on hematological malignancies, there are several molecules in clinical development that are directed towards non-hematological cancers. Our review focuses on clinical development of bi-specific and tri-specific antibodies directed towards solid tumors.

\section{Advantages and disadvantages of polyspecific monoclonal antibodies}

Polyspecific monoclonal antibodies (PsMabs) are genetically engineered proteins that can simultaneously engage two or more different types of epitopes (Figs. 1a, b and 2) (Fan et al. 2015; Zhang et al. 2017). They show several advantages over monoclonal antibodies (Fig. 2) in that they can: 1) redirect specific polyclonal immune cells such as T cells and NK cells to tumor cells to enhance tumor killing, 2) simultaneously block two different pathways with unique or overlapping functions in pathogenesis, 3) potentially increase binding specificity by interacting with two different cell surface antigens instead of one, and 4) reduce cost in terms of development and production when compared to multiple single based antibodies used in combination therapy or compared to the production of CAR-T cells. The advantages and disadvantages of polyspecific antibodies are tabulated in Table 1.

\section{PsMab formats}

Bispecific antibodies with ability to engage two different antigens are the most commonly used PsMabs. Since the initial experiments to produce BsMabs (Holliger and Winter 1993), the products have undergone major transformation (Brinkmann and Kontermann 2017) and have proved useful in cancer diagnosis, imaging, and treatment. The differences in the first generation BsMabs and the newer molecules are tabulated in Table 2. The components of polyspecific antibodies used today range from full antibody structures to fragments, with creation of structures only limited by the vision of the molecular chemist, patenting rules, physiochemical constraints, and clinical utility. Some of the BsMab manufactured today include bispecific small molecule-antibody conjugates, chemical hetero-conjugates, and protein genetic engineering involving recombinant DNA technology (Spiess et al. 2015; Brinkmann and Kontermann 2017). The most studied structures are shown in Fig. 1a and b. In general, these bispecific antibodies are divided into two major classes: IgG like bispecific antibodies which carry an Fc region and therefore retain Fc-mediated effector functions and the non-IgG like formats which rely entirely on their antigen binding capacity to exert therapeutic effects. The differences between these two classes are highlighted in Table 3. Fc mediated effector functions include antibody-dependent cell mediated toxicity (ADCC), antibody dependent cellular phagocytosis (ADCP), complement-dependent cyototoxicity, and the binding of the molecules to the neonatal $\mathrm{Fc}_{\mathrm{c}}$ receptor $(\mathrm{FcRn})$ which protects IgG from degradation and increases the molecular half-life (Fan et al. 2015).

In the past, IgG-like BsAbs were created by chemical conjugation or hybridoma techniques. These were cumbersome, time-consuming procedures and resulted in creation of nonfunctional molecules through random assembly of different heavy and light chains in addition to intended bispecific antibodies (Staerz et al. 1985). These shortcomings can be improved using recombinant DNA technology. For example, bispecific tetravalent molecules such as dual-variable-domain immunoglobulin (DVD-Ig) can now be produced by combining two target-binding monoclonal antibodies via naturally occurring linkers and optimizing yield of viable molecules through advanced recombinant DNA techniques (Spiess et al. 2015). The simultaneous binding of antigen to all variable domains in dual variable domain immunoglobulin (DVD-Ig) provide a higher specific binding capacity which could be used in targeting low abundance proteins such as cytokines (Sedykh et al. 2018) and potentially also allow the drug to be dosed less frequently.

Recombinant techniques have also led to the creation of small fragment molecules by combining single chain variable fragments from two different monoclonal antibodies to form bivalent bispecific "antibodies" ranging in size from 50 to $60 \mathrm{kDa}$ (Kontermann 2012). Some examples of these are the bispecific T cell engager (BiTE), tandem single chain variable fragments (taFvs), diabodies (Dbs), single chain diabodies (scDbs), and triplebodies. Due to their small size, these scFV based antibody fragments have high tumor specificity and tumor penetration. However, their small size also limits serum half-lives which could potentially limit efficacy and increase cost by requiring repetitive dosing (Zhang et al. 2017). By fusing these antibody fragments with albumin or proteins that bind albumin, the serum half-life can be 


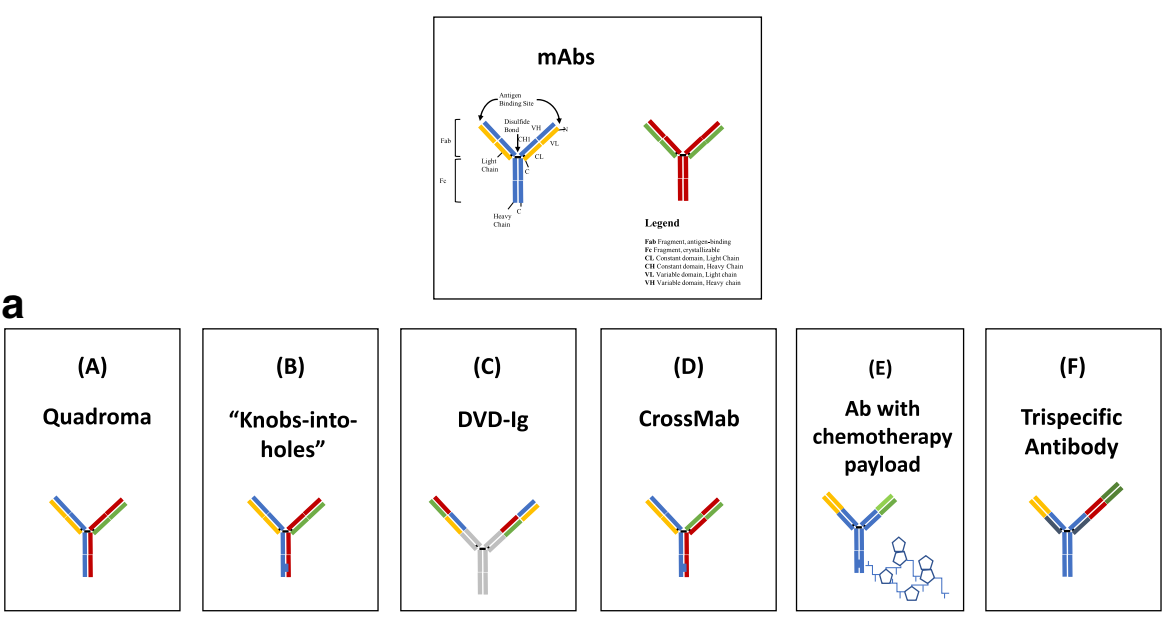

a

b
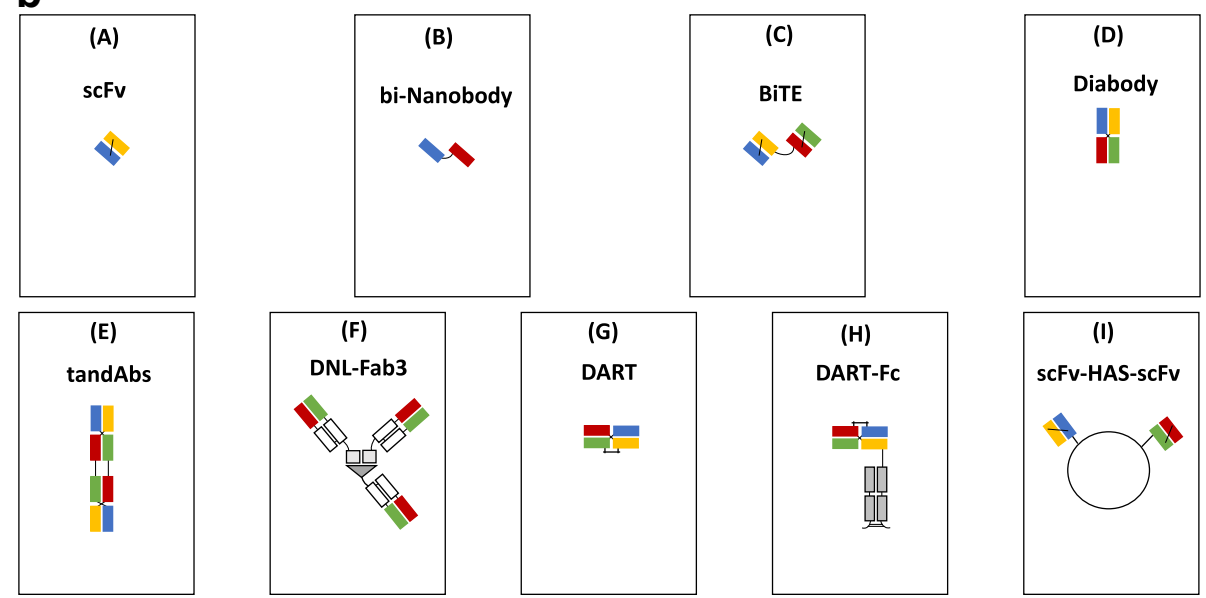

Fig. 1 a: Some formats of lgG -like bispecific antibodies and a trispecific antibody. (A) Quadroma created by combining the light and heavy chains of two different monoclonal antibodies resulting in two antigen binding sites aimed at different tumor antigens eg. Catumaxomab (B) Two antibody chains with engineered CH3 domain to create a "knob" in one heavy chain and a "hole" in the other to promote heterodimerization. This allows only specific pairing of heavy chains to reduce mispairing. (C) Variable domains of two mABs fused to create a dual- specific antibody (D) CrossMab exchanging of the $\mathrm{CH} 1$ domain of one heavy chain with the constant domain of the corresponding light chain for better light chain pairing (E) Bispecific antibody with two unique antigen-binding sites and a chemotherapy payload attached to the constant domain (F) Trispecific antibody engineered to bind to three different ligands on tumor cell. $\mathbf{b}$ : Some formats of bispecific antibody fragments and fusion proteins. (A) scFvs - Combination of the variable region of one light chain with the variable region of one heavy chain fragment is the basic element for antigen binding. (B) bi-Nanobody-Combination of two different single variable heavy chain domains which are able to bind different tumor antigens. (C) BiTE- Tandem single chain variable fragments from different antibodies joined by a flexible peptide chain. (D) Diabody - Bivalent molecules composed of two chains each comprising a variable light chain and variable heavy chain domain, either from the same or different antibodies. (E) TandAbs - Two pairs of variable light chain and variable heavy chain domains are connected in a single polypeptide chain to form a tetravalent tandAb. (F) DNL-Fab3 - Trivalent bispecific antibody composed of three Fab fragments joined by the utilization of the specific interaction between the regulatory subunits of cyclic adenosine monophosphate (CAMP)-dependent protein kinase A (PKA) and the anchoring domains of A kinase anchoring proteins (AKAP). (G) DART - Two polypeptide chains derived from the variable heavy chain from one molecule linked to a variable light chain of another molecule. (H) DART-Fc - DARTs with a Fc fragment designed to prolong serum retention time. (I) scFv-HAS-scFV- Association of two single chain variable fragments through modified dimerization domains

prolonged by five or six times (Sedykh et al. 2018). Other methods such as PEGylation, Fc fragment fusion, and multimerization are also being explored to extend antibody serum half-life (Fan et al. 2015). The major advantages and disadvantages of IgG - like bispecific antibodies and bispecific antibody fragments are listed in Table 3.
The BiTE warrants special mention as one of the binding sites is engineered to bring an effector cell ( $\mathrm{T}$-cell or NK cell) into the proximity of the tumor cell to enhance antitumor effect (Fig. 2). This function results in more effective tumor cell lysis relative to other bispecific formats and monoclonal antibodies (Yang et al. 2016). In the case of T-cells, the target site for binding is 


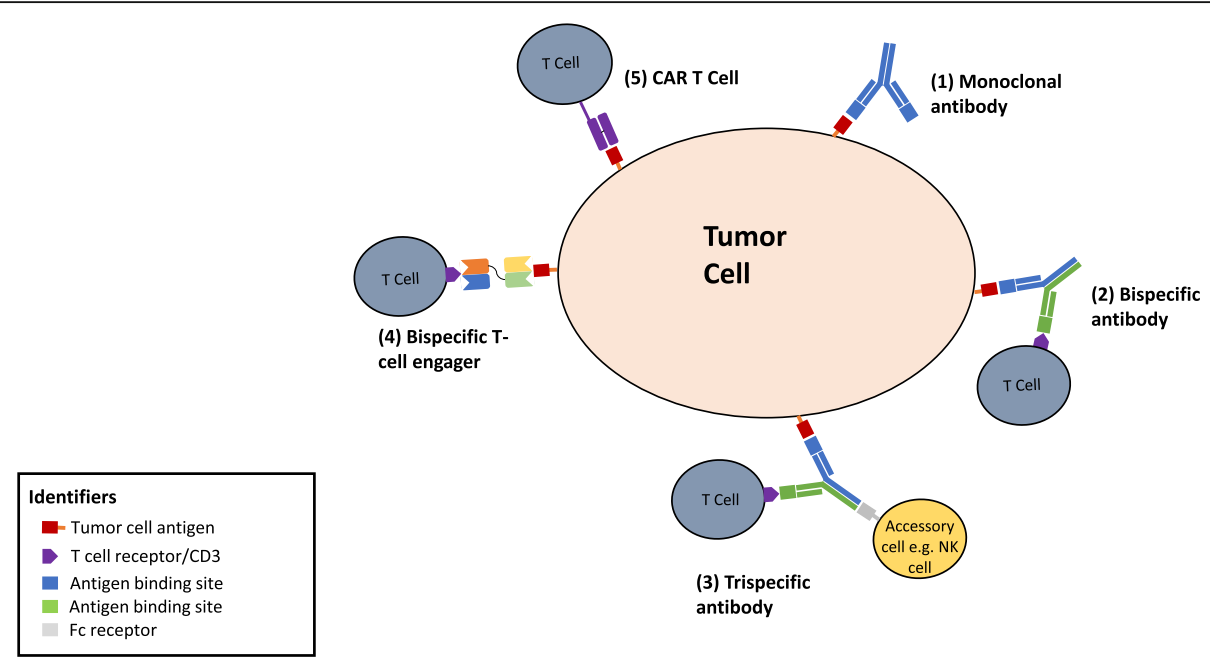

Fig. 2 Schematic showing different formats of immunotherapy binding to the antigen on the tumor cell: (1) monoclonal antibody, (2) bispecific antibody, (3) trispecific antibody, (4) bispecific T cell engager made from two single chain antibody fragments, and (5) CAR T cell therapy which is comprised of light chain and heavy chain variable fragments joined by a flexible linker

commonly CD3. The bi-specific binding of a white cell to the target mimics the action for an activated white cell against its target (Offner et al. 2006). This functionality of bispecific antibody which can use non-HLA restricted white cells without in vitro expansion was described in 1985 but could not be exploited until

Table 1 Advantages and disadvantages of polyspecific antibodies over monospecific antibodies

\begin{tabular}{|c|c|}
\hline Advantages & Disadvantages \\
\hline $\begin{array}{l}\text { Amenable for large scale } \\
\text { production }\end{array}$ & $\begin{array}{l}\text { Hetero-dimerization of chains may } \\
\text { make the molecule inefficient; early } \\
\text { methods had low production } \\
\text { yields }\end{array}$ \\
\hline More efficient binding to target & Steric inhibition of engaging sites \\
\hline $\begin{array}{l}\text { Able to engage T cell or NK cells } \\
\text { (MHC agnostic) by a cell } \\
\text { combining site }\end{array}$ & $\begin{array}{l}\text { Potential antigenic cytokine release } \\
\text { syndrome }\end{array}$ \\
\hline Stability & $\begin{array}{l}\text { Small molecules can be rapidly } \\
\text { cleared; larger ones may aggregate; } \\
\text { potential immunogenicity }\end{array}$ \\
\hline Not patient specific; target specific & $\begin{array}{l}\text { Tight white cell binding may } \\
\text { change bio-distribution }\end{array}$ \\
\hline $\begin{array}{l}\text { Can be a carrier of radioisotope or } \\
\text { chemotherapy }\end{array}$ & $\begin{array}{l}\text { Potential poor internalization of } \\
\text { molecule if combined with } \\
\text { cytotoxic agent }\end{array}$ \\
\hline Can be used for imaging & Need for external epitope \\
\hline Can serve as an immune enhancer & $\begin{array}{l}\text { Affinity for target epitope and } \\
\text { effector cell critical }\end{array}$ \\
\hline $\begin{array}{l}\text { Can be encapsulated in a } \\
\text { liposome }\end{array}$ & $\begin{array}{l}\text { Large molecules have less intra- } \\
\text { tumoral penetration. }\end{array}$ \\
\hline $\begin{array}{l}\text { Can be combined with other } \\
\text { immunological agents }\end{array}$ & $\begin{array}{l}\text { May enhance toxicity if combined } \\
\text { with classical immunological } \\
\text { agents }\end{array}$ \\
\hline Bystander effect & \\
\hline
\end{tabular}

recently (Staerz et al. 1985). Another advantage of this approach is a bystander effect on adjacent cells which may be of value in a tumor with heterogeneous expression of target epitope (Ross et al. 2017). It was recently noted in a study looking at the bio-distribution of a T-cell dependent bi-specific antibody in a murine model of human HER2 breast cancer that the binding affinity for the white cell can determine whether or not the bi-specific antibody/white cell combination can reach the target site or becomes trapped in lymphatic organs (Mandikian et al. 2018). Hence, negative studies with bi-specific antibodies may be in part due to lack of target cell engagement due to poor distribution.

The diabody format which has two variable domains of two different antibodies connected by two linkers has more stability than BiTEs but the linkers restrict the mobility of the antigen binding sites limiting antigen recognition (Fan et al. 2015). DART bispecific antibodies, created by engineering two Fv fragments with the variable heavy chain portion exchanged with one another, are larger than BITEs and show better serum stability (Zhang et al. 2017). The Dock-and-Lock (DNL) recombinant method (Fig. 1b) creates multivalency and multifunctionality with bispecific antibody fragments (Rossi et al. 2006). These later generation formats such as BiTE, dual-affinity re-targeting antibodies (DART) antibodies, tandem diabodies appear to potently eliminate targets expressing their tumor associated antigen (TAA) in the absence of costimulatory models or IL-2 pre-activated T cells (Zhukovsky et al. 2016).

\section{PsMab in clinical use}

Currently, there is only one bi-specific antibody approved for cancer therapy. The first bispecific antibody 
Table 2 Production, limitations, and examples of first and subsequent generations of BsMab

\begin{tabular}{|c|c|}
\hline EarlierBsMab & NewerBsMab \\
\hline $\begin{array}{l}\text { Produced by oxidative } \\
\text { recombination, chemical } \\
\text { cross-linking, and enzymatic } \\
\text { digestion of desired antibodies } \\
\text { to yield Fab fragments which } \\
\text { are then combined via } \\
\text { bifunctional reagents } \\
\text { to form a heterodimer }{ }^{21,22} \text {. }\end{array}$ & $\begin{array}{l}\text { Produced by advanced techniques } \\
\text { such as controlled Fab-arm } \\
\text { exchange (cFAE), improvised } \\
\text { somatic fusion of two hybridoma } \\
\text { cell lines (quadroma), small } \\
\text { molecule-antibody conjugation, } \\
\text { genetic engineering using } \\
\text { molecular cloning technology }{ }^{20} \text {. }\end{array}$ \\
\hline $\begin{array}{l}\text { Inability to produce large } \\
\text { quantities }\end{array}$ & $\begin{array}{l}\text { Shorter processing time and ability } \\
\text { to produce in large-scale. }\end{array}$ \\
\hline $\begin{array}{l}\text { Rapid destruction of murine } \\
\text { antibody fragments }\end{array}$ & Stability and longer half-life. \\
\hline Difficult to purify & $>90 \%$ pure \\
\hline $\begin{array}{l}\text { Examples: MDX-210 }{ }^{23} \text { (targeting } \\
\text { Her2, and CD } 64 \text { or FcyRI which is } \\
\text { expressed on monocytes, macro- } \\
\text { phages and activated neutrophils; } \\
\text { MDX-447 }{ }^{24} \text { (targeting EGFR and } \\
\text { CD 64; } \\
\text { HRS-3/49- Targeting CD } 30 \text { on } \\
\text { Reed Sternberg cells in Hodgkin } \\
\text { lymphoma and FcyRIII or CD } 16 \text { on } \\
\text { natural killer cells and } \\
\text { macrophages. }\end{array}$ & $\begin{array}{l}\text { Examples: Catumaxomab and } \\
\text { Solitomab (targeting EpCAM } \\
\text { expressed on breast, ovarian and } \\
\text { other cancer cells as well as CD3 } \\
\text { on T cells-bispecific T cell engager } \\
\text { or BiTE) }{ }^{23,26,27} \text {; Blinatumomab } \\
\text { (binding to both CD19 on B cell } \\
\text { cells and CD3 on T cells). }\end{array}$ \\
\hline
\end{tabular}

to enter clinic, Catumaxomab was approved by European Union for use in malignant ascites in 2009 (Seimetz 2009). Catumaxomab is a trifunctional antibody produced by a rat-mouse quadroma cell with affinities to CD3 antigen on cytotoxic T cells and epithelial cell adhesion molecule (EpCAM) which is a type 1 transmembrane glycoprotein associated with malignant ascites and effusions and expressed on the majority of epithelial cancers (Linke et al. 2010; Seimetz 2011). The approval was based on studies showing the efficacy of intraperitoneal

Table 3 Comparing different formats of bispecific antibodies

\begin{tabular}{|c|c|c|}
\hline $\begin{array}{l}\text { Antibody } \\
\text { format }\end{array}$ & Advantages & Disadvantages \\
\hline \multirow{3}{*}{$\begin{array}{l}\text { lgG- like } \\
\text { bispecifc } \\
\text { antibodies }\end{array}$} & Longer half life & \multirow{3}{*}{$\begin{array}{l}\text { Fc region more } \\
\text { immunogenic }\end{array}$} \\
\hline & $\begin{array}{l}\text { Fc domain facilitates } \\
\text { efficient purification }\end{array}$ & \\
\hline & $\begin{array}{l}\text { Fc domain able to trigger } \\
\text { antibody dependent cell } \\
\text { mediated toxicity, } \\
\text { complement dependent cell } \\
\text { mediated toxicity }\end{array}$ & \\
\hline \multirow{4}{*}{$\begin{array}{l}\text { Bispecific } \\
\text { Antibody } \\
\text { Fragments }\end{array}$} & High tumor specificity & \multirow{4}{*}{$\begin{array}{l}\text { Small size make them } \\
\text { prone to elimination i.e. } \\
\text { shorter half-life }\end{array}$} \\
\hline & Good tissue penetration & \\
\hline & $\begin{array}{l}\text { Small formats can allow close } \\
\text { contacts between effector } \\
\text { and target cells forming } \\
\text { efficient immune synapses } \\
\text { not requiring co-stimulatory } \\
\text { molecules }\end{array}$ & \\
\hline & Easy to manufacture & \\
\hline
\end{tabular}

administration of Catumaxomab in improving symptoms and signs of malignant ascites and reducing the need for paracentesis (Heiss et al. 2010; Frampton 2012). A positive trend of overall survival in patients with malignant ascites associated with epithelial cancers was also noted in a prospective randomized trial (Heiss et al. 2010; Frampton 2012) and there was demonstrable activity in platinum refractory epithelial ovarian cancer (Baumann et al. 2011). The drug was deemed safe for use in outpatient setting in patients with malignant ascites secondary to gynecological tumors including epithelial ovarian cancer and metastatic breast cancer (Kurbacher et al. 2015). Although Catumaxomab showed promising results, it was taken off the market in 2014 due to financial reasons. Its approval was subsequently withdrawn in 2017 (No Title. https://neovii.com/neovii-completes-marketing-authorisation-withdrawal-of-removab-in-the-european-union/ n.d.).

The bi-specific antibody Blinatumomab was approved by the US FDA in December 2014 for the treatment of acute B-cell acute lymphoblastic leukemia (ALL). Blinatumomab is a novel bi-specific $\mathrm{T}$ cell engager which binds sites for both CD19 (antigen expressed on all stages of B cell lineage) and CD3 T cell receptor complex, leading to T cell proliferation and activation resulting in target cell (lymphoblast) apoptosis. Unlike catumaxomab, which uses large IgG-like bi-specific antibodies with Fc regions, blinatumomab was created by the fusion of two single chain variable fragments $(\mathrm{scFv})$ connected in a flexible manner through a peptide linker (Newman and Benani 2016). It has been shown to induce durable responses in patients with B cell malignancies and was quickly approved after phase II trial of adult patients with Philadelphia-chromosome-negative relapsed or refractory B-precursor ALL, 43\% (81 out of 189) of patients reached the primary endpoint of complete hematological response (Topp et al. 2014). A subsequent multi-institutional phase 3 trial evaluated blinatumomab to standard-of-care chemotherapy in heavily pre-treated B-cell precursor ALL confirmed excellent activity of the drug in these patients with improved outcomes, including overall and progression-free-survivals (Kantarjian et al. 2017).

\section{Other agents including those in development}

The clinical success of these engineered antibodies has ushered in a phase of rapid development of new agents for the treatment of various solid tumor malignancies. Many tyrosine kinase receptors which are integral in regulating the pathway of cell growth, cell differentiation, cell migration, and cell death are prime targets for most of these molecules ( $\mathrm{Yu}$ et al. 2017; Kalyankrishna and Grandis 2006; Loibl and Gianni 2017; Ooi et al. 2004; Shinojima et al. 2003). A few examples are highlighted here and a detailed log of ongoing clinical trials is presented in Table 4. 
Table 4 Recent clinical trials involving the use of bispecific antibodies in solid tumor malignancies

\begin{tabular}{|c|c|c|c|c|c|c|c|}
\hline Drug name & Antibody type & Sponsor & $\begin{array}{l}\text { Target } \\
\text { antigens }\end{array}$ & $\begin{array}{l}\text { Development } \\
\text { stage }\end{array}$ & Indication & Status & $\begin{array}{l}\text { Clinical trials } \\
\text { identifier }\end{array}$ \\
\hline $\begin{array}{l}\text { Selicrelumab } \\
\text { Vanucizumab } \\
\text { Bevacizumab }\end{array}$ & CrossMab & $\begin{array}{l}\text { Hoffmann-La } \\
\text { Roche }\end{array}$ & Ang2, VEGF & Phase I & $\begin{array}{l}\text { Advanced/ Metastatic Solid } \\
\text { Tumors }\end{array}$ & Recruiting & NCT02665416 \\
\hline $\begin{array}{l}\text { rM28, autologous } \\
\text { PBMCs }\end{array}$ & Tandem ScFv & $\begin{array}{l}\text { University Hospital } \\
\text { Tuebingen }\end{array}$ & $\begin{array}{l}\text { CD28, } \\
\text { HMV-MMA }\end{array}$ & $\begin{array}{l}\text { Phase I/Phase } \\
\|\end{array}$ & $\begin{array}{l}\text { Stage III/IV metastatic } \\
\text { melanoma }\end{array}$ & Completed & NCT00204594 \\
\hline $\begin{array}{l}\text { Indium labeled } \\
\text { IMP-205xm734 }\end{array}$ & $\begin{array}{l}\text { IgG type } \\
\text { bispecific } \\
\text { antibody }\end{array}$ & $\begin{array}{l}\text { Radboud } \\
\text { University }\end{array}$ & CEA & Phase I & Colorectal carcinoma & Completed & NCT00185081 \\
\hline $\begin{array}{l}\text { Obinutuzumab, } \\
\text { RO6958688 }\end{array}$ & $\begin{array}{l}\text { IgG type T cell } \\
\text { bispecific } \\
\text { antibody }\end{array}$ & $\begin{array}{l}\text { Hoffmann-La } \\
\text { Roche }\end{array}$ & CEA, CD3 & Phase I & $\begin{array}{l}\text { Locally advanced or Metastatic } \\
\text { Solid Tumors }\end{array}$ & $\begin{array}{l}\text { Active, not } \\
\text { recruiting }\end{array}$ & NCT02324257 \\
\hline MEDI 565 & BITE & Medlmmune LLC & CEA, CD3 & Phase I & $\begin{array}{l}\text { Gastrointestinal } \\
\text { Adenocarcinomas }\end{array}$ & Completed & NCT01284231 \\
\hline $\begin{array}{l}\text { Anti-CEA } x \text { anti- } \\
\text { DTPA }\end{array}$ & $\begin{array}{l}\text { Fusion of two } \\
\text { Fab fragments }\end{array}$ & $\begin{array}{l}\text { Nantes University } \\
\text { Hospital }\end{array}$ & CEA, DTPA & Phase II & Medullary Thyroid Carcinoma & Completed & NCT00467506 \\
\hline $\begin{array}{l}\text { anti-CEA } x \text { anti- } \\
\text { HSG TF-2 }\end{array}$ & $\begin{array}{l}\text { Dock and lock } \\
\text { bispecific } \\
\text { antibody }\end{array}$ & $\begin{array}{l}\text { Garden State } \\
\text { Cancer Center at } \\
\text { the Center for } \\
\text { Molecular } \\
\text { Medicine and } \\
\text { Immunology }\end{array}$ & CEA, HSG & Phase I & $\begin{array}{l}\text { Detection of Colorectal } \\
\text { Carcinoma }\end{array}$ & Unknown & NCT00895323 \\
\hline $\begin{array}{l}\text { TF2 antibody/ } \\
\text { 68Ga-IMP-288 }\end{array}$ & $\begin{array}{l}\text { Gallium labeled } \\
\text { Dock and lock } \\
\text { bispecific } \\
\text { antibody }\end{array}$ & $\begin{array}{l}\text { Nantes University } \\
\text { Hospital }\end{array}$ & CEA, HSG & Phase II & Metastatic Colorectal Cancer & Completed & NCT02587247 \\
\hline $\begin{array}{l}\text { TF2-68 Ga-IMP- } \\
288\end{array}$ & $\begin{array}{l}\text { Gallium labeled } \\
\text { Dock and lock } \\
\text { bispecific } \\
\text { antibody }\end{array}$ & $\begin{array}{l}\text { Nantes University } \\
\text { Hospital }\end{array}$ & CEA, HSG & $\begin{array}{l}\text { Phase I/Phase } \\
\|\end{array}$ & $\begin{array}{l}\text { HER2 negative Breast } \\
\text { Carcinoma expressing CEA }\end{array}$ & $\begin{array}{l}\text { Active, not } \\
\text { recruiting }\end{array}$ & NCT01730612 \\
\hline $\begin{array}{l}\text { Anti- CEA } \times \text { Anti- } \\
\text { HSG TF2, Radiation }\end{array}$ & $\begin{array}{l}\text { Dock and lock } \\
\text { bispecific } \\
\text { antibody }\end{array}$ & $\begin{array}{l}\text { Centre René } \\
\text { Gauducheau }\end{array}$ & CEA, HSG & $\begin{array}{l}\text { Phase I/Phase } \\
\|\end{array}$ & $\begin{array}{l}\text { Small Cell Lung Cancer } \\
\text { CEA-Expressing NSCLC }\end{array}$ & Completed & NCT01221675 \\
\hline $\begin{array}{l}\text { TF2 and } 68 \mathrm{Ga}- \\
\text { IMP-288 }\end{array}$ & $\begin{array}{l}\text { Gallium labeled } \\
\text { Dock and lock } \\
\text { bispecific } \\
\text { antibody }\end{array}$ & $\begin{array}{l}\text { Nantes University } \\
\text { Hospital }\end{array}$ & CEA, HSG & $\begin{array}{l}\text { Phase I/ } \\
\text { Phase II }\end{array}$ & Medullary Thyroid Carcinoma & Completed & NCT01730638 \\
\hline $\begin{array}{l}\text { TF-2, IMP-288 la- } \\
\text { beled with In111 } \\
\text { and Lu177 }\end{array}$ & $\begin{array}{l}\text { Dock and lock } \\
\text { bispecific } \\
\text { antibody }\end{array}$ & $\begin{array}{l}\text { Radboud } \\
\text { University }\end{array}$ & $\begin{array}{l}\text { CEA, } \\
\text { Lu177- } \\
\text { labeled } \\
\text { peptide }\end{array}$ & Phase I & Colorectal cancer & Completed & NCT00860860 \\
\hline AMG 757 & BITE & Amgen & DLL3 & Phase I & Small Cell Lung Cancer & Recruiting & NCT03319940 \\
\hline NOV1501 & $\begin{array}{l}\text { lgG type } \\
\text { bispecific } \\
\text { antibody }\end{array}$ & $\begin{array}{l}\text { National } \\
\text { OncoVenture }\end{array}$ & DLL4, VEGF & Phase I & Advanced Solid Tumors & Recruiting & NCT03292783 \\
\hline OMP-305B83 & $\begin{array}{l}\text { IgG type } \\
\text { bispecific } \\
\text { monoclonal } \\
\text { antibody }\end{array}$ & $\begin{array}{l}\text { OncoMed } \\
\text { Pharmaceuticals }\end{array}$ & DLL4, VEGF & Phase I & Metastatic Colorectal Cancer & Recruiting & NCT03035253 \\
\hline OMP-305B83 & $\begin{array}{l}\text { IgG type } \\
\text { bispecific } \\
\text { monoclonal } \\
\text { antibody }\end{array}$ & $\begin{array}{l}\text { OncoMed } \\
\text { Pharmaceuticals }\end{array}$ & DLL4, VEGF & Phase I & Previously Treated Solid Tumors & $\begin{array}{l}\text { Active, not } \\
\text { recruiting }\end{array}$ & NCT02298387 \\
\hline $\begin{array}{l}\text { OMP-305B83, } \\
\text { Paclitaxel }\end{array}$ & $\begin{array}{l}\text { IgG type } \\
\text { bispecific } \\
\text { monoclonal } \\
\text { antibody }\end{array}$ & $\begin{array}{l}\text { OncoMed } \\
\text { Pharmaceuticals }\end{array}$ & DLL4, VEGF & Phase I & $\begin{array}{l}\text { Ovarian, Peritoneal or Fallopian } \\
\text { Tube Cancer }\end{array}$ & Recruiting & NCT03030287 \\
\hline EEDVsMit & $\begin{array}{l}\text { Nanocell coated } \\
\text { with lgG type }\end{array}$ & Dr. David Ziegler & EGFR & Phase I & $\begin{array}{l}\text { Refractory solid or CNS tumors } \\
\text { expressing EGFR }\end{array}$ & Recruiting & NCT02687386 \\
\hline
\end{tabular}


Table 4 Recent clinical trials involving the use of bispecific antibodies in solid tumor malignancies (Continued)

\begin{tabular}{|c|c|c|c|c|c|c|c|}
\hline Drug name & Antibody type & Sponsor & $\begin{array}{l}\text { Target } \\
\text { antigens }\end{array}$ & $\begin{array}{l}\text { Development } \\
\text { stage }\end{array}$ & Indication & Status & $\begin{array}{l}\text { Clinical trials } \\
\text { identifier }\end{array}$ \\
\hline & $\begin{array}{l}\text { bispecific } \\
\text { antibody and } \\
\text { mitoxantrone } \\
\text { payload }\end{array}$ & & & & & & \\
\hline $\begin{array}{l}\text { EGFR (V)- EDV- } \\
\text { Dox }\end{array}$ & $\begin{array}{l}\text { Nanocell coated } \\
\text { with lgG type } \\
\text { bispecific } \\
\text { antibody and } \\
\text { doxorubicin } \\
\text { payload }\end{array}$ & $\begin{array}{l}\text { Engeneic Pty } \\
\text { Limited }\end{array}$ & EGFR & Phase I & $\begin{array}{l}\text { Recurrent Glioblastoma } \\
\text { Multiforme }\end{array}$ & Recruiting & NCT02766699 \\
\hline TargomiRs & $\begin{array}{l}\text { Nanocell coated } \\
\text { with IgG type } \\
\text { bispecific } \\
\text { antibody } \\
\text { containing } \\
\text { microRNA }\end{array}$ & $\begin{array}{l}\text { Asbestos Disease } \\
\text { Research } \\
\text { Foundation }\end{array}$ & EGFR & Phase I & $\begin{array}{l}\text { Recurrent malignant pleural } \\
\text { mesothelioma } \\
\text { Non-small cell lung cancer }\end{array}$ & Completed & NCT02369198 \\
\hline MDX447 & $\begin{array}{l}\text { IgG type } \\
\text { bispecific } \\
\text { antibody }\end{array}$ & $\begin{array}{l}\text { Dartmouth- } \\
\text { Hitchcock Medical } \\
\text { Center }\end{array}$ & EGFR & Phase I & $\begin{array}{l}\text { Brain and Central Nervous } \\
\text { System Tumors }\end{array}$ & Completed & NCT00005813 \\
\hline $\begin{array}{l}\text { Anti-CD3x anti- } \\
\text { EGFR bispecific } \\
\text { armed activated T } \\
\text { cells (BATs), } \\
\text { Aldesleukin, } \\
\text { Sargramostim }\end{array}$ & $\begin{array}{l}\text { T cells } \\
\text { preloaded with } \\
\text { lgG type } \\
\text { bispecific } \\
\text { antibody }\end{array}$ & $\begin{array}{l}\text { Barbara Ann } \\
\text { Karmanos Cancer } \\
\text { Institute }\end{array}$ & EGFR, CD3 & $\begin{array}{l}\text { Phase I/ } \\
\text { Phase II }\end{array}$ & $\begin{array}{l}\text { Locally advanced, metastatic, or } \\
\text { recurrent pancreatic cancer }\end{array}$ & $\begin{array}{l}\text { Active, not } \\
\text { recruiting }\end{array}$ & NCT02620865 \\
\hline EGFR BATs & $\begin{array}{l}\text { T cells } \\
\text { preloaded with } \\
\text { lgG type } \\
\text { bispecific } \\
\text { antibody }\end{array}$ & $\begin{array}{l}\text { University of } \\
\text { Virginia }\end{array}$ & EGFR, CD3 & $\begin{array}{l}\text { Phase I/ } \\
\text { Phase II }\end{array}$ & $\begin{array}{l}\text { Locally advanced and } \\
\text { metastatic pancreatic cancer }\end{array}$ & Recruiting & NCT03269526 \\
\hline $\begin{array}{l}\text { Anti-CD3 } \times \text { Anti- } \\
\text { EGFR BATs with ra- } \\
\text { diation and } \\
\text { temozolomide }\end{array}$ & $\begin{array}{l}\text { T cells } \\
\text { preloaded with } \\
\text { lgG type } \\
\text { bispecific } \\
\text { antibody }\end{array}$ & $\begin{array}{l}\text { University of } \\
\text { Virginia }\end{array}$ & EGFR, CD3 & Phase I & Glioblastoma Multiforme & Recruiting & NCT03344250 \\
\hline JNJ-61186372 & $\begin{array}{l}\text { IgG1 type } \\
\text { bispecific } \\
\text { antibody }\end{array}$ & $\begin{array}{l}\text { Janssen Research } \\
\text { and Development } \\
\text { LLC }\end{array}$ & EGFR, cMet & Phase I & $\begin{array}{l}\text { Advanced non-small cell lung } \\
\text { cancer }\end{array}$ & Recruiting & NCT02609776 \\
\hline MCLA-158 & $\begin{array}{l}\lg G 1 \text { bispecific } \\
\text { antibody }\end{array}$ & Merus N.V. & EGFR, LGR5 & Phase I & $\begin{array}{l}\text { Metastatic Colorectal Cancer } \\
\text { and select advanced solid } \\
\text { tumors }\end{array}$ & Recruiting & NCT03526835 \\
\hline Catumaxomab & $\begin{array}{l}\text { Trifunctional lgG } \\
\text { type antibody }\end{array}$ & AGO Study Group & $\begin{array}{l}\text { EpCAM, } \\
\text { CD3 }\end{array}$ & Phase ॥ & $\begin{array}{l}\text { Ovarian cancer, Fallopian Tube } \\
\text { Neoplasms, Peritoneal } \\
\text { Neoplasms }\end{array}$ & Completed & NCT00189345 \\
\hline Catumaxomab & $\begin{array}{l}\text { Trifunctional lgG } \\
\text { type antibody }\end{array}$ & Neovii Biotech & $\begin{array}{l}\text { EpCAM, } \\
\text { CD3 }\end{array}$ & $\begin{array}{l}\text { Phase II/Phase } \\
\text { III }\end{array}$ & $\begin{array}{l}\text { Malignant ascites } \\
\text { EpCam positive tumors }\end{array}$ & Completed & NCT00836654 \\
\hline Catumaxomab & $\begin{array}{l}\text { Trifunctional lgG } \\
\text { type antibody }\end{array}$ & Neovii Biotech & $\begin{array}{l}\text { EpCAM, } \\
\text { CD3 }\end{array}$ & Phase II & $\begin{array}{l}\text { Gastric Adenocarcinoma after } \\
\text { neoadjuvant chemotherapy } \\
\text { and curative resection }\end{array}$ & Completed & NCT00464893 \\
\hline Catumaxomab & $\begin{array}{l}\text { Trifunctional lgG } \\
\text { type antibody }\end{array}$ & Neovii Biotech & $\begin{array}{l}\text { EpCAM, } \\
\text { CD3 }\end{array}$ & Phase II & $\begin{array}{l}\text { Gastric Adenocarcinoma after } \\
\text { curative resection }\end{array}$ & Completed & NCT00352833 \\
\hline MT110 & BITE & $\begin{array}{l}\text { Amgen Research } \\
\text { (Munich) }\end{array}$ & $\begin{array}{l}\text { EpCAM, } \\
\text { CD3 }\end{array}$ & Phase I & $\begin{array}{l}\text { Gastric Cancer or } \\
\text { Adenocarcinoma of the Gastro- } \\
\text { esophageal Junction, Colorectal } \\
\text { Cancer, Breast Cancer, } \\
\text { Hormone-Refractory Prostate } \\
\text { Cancer, Ovarian Cancer }\end{array}$ & Completed & NCT00635596 \\
\hline GD2Bi-aATC & $\begin{array}{l}\text { T cells } \\
\text { preloaded with }\end{array}$ & $\begin{array}{l}\text { Barbara Ann } \\
\text { Karmanos Cancer }\end{array}$ & GD2 & Phase I/ II & $\begin{array}{l}\text { Desmoplastic small round cell } \\
\text { tumor, Disseminated }\end{array}$ & Recruiting & NCT02173093 \\
\hline
\end{tabular}


Table 4 Recent clinical trials involving the use of bispecific antibodies in solid tumor malignancies (Continued)

\begin{tabular}{|c|c|c|c|c|c|c|c|}
\hline Drug name & Antibody type & Sponsor & $\begin{array}{l}\text { Target } \\
\text { antigens }\end{array}$ & $\begin{array}{l}\text { Development } \\
\text { stage }\end{array}$ & Indication & Status & $\begin{array}{l}\text { Clinical trials } \\
\text { identifier }\end{array}$ \\
\hline & $\begin{array}{l}\text { lgG type } \\
\text { bispecific } \\
\text { antibody }\end{array}$ & Institute & & & $\begin{array}{l}\text { neuroblastoma, Metastatic } \\
\text { Osteosarcoma, Recurrent } \\
\text { Neuroblastoma, Recurrent } \\
\text { Osteosarcoma }\end{array}$ & & \\
\hline MGD007 & DART & MacroGenics & $\begin{array}{l}\text { gpA33, } \\
\text { CD3 }\end{array}$ & Phase I & $\begin{array}{l}\text { Relapsed/Refractory Metastatic } \\
\text { Colorectal Cancer }\end{array}$ & Recruiting & NCT02248805 \\
\hline $\begin{array}{l}\text { MGD007 and } \\
\text { MGA012 }\end{array}$ & DART & MacroGenics & $\begin{array}{l}\text { gpA33, } \\
\text { CD3, PD-1 }\end{array}$ & $\begin{array}{l}\text { Phase I/ } \\
\text { Phase II }\end{array}$ & $\begin{array}{l}\text { Relapsed/ Refractory Metastatic } \\
\text { Colon Cancer }\end{array}$ & Recruiting & NCT03531632 \\
\hline ERY974 & $\begin{array}{l}\text { lgG4 bispecific T } \\
\text { cell-redirecting } \\
\text { antibody }\end{array}$ & $\begin{array}{l}\text { Chugai } \\
\text { Pharmaceutical }\end{array}$ & GPC3, CD3 & Phase I & Solid Tumors & Recruiting & NCT02748837 \\
\hline MM-111 & $\begin{array}{l}\text { Bispecific } \\
\text { antibody fusion } \\
\text { protein }\end{array}$ & $\begin{array}{l}\text { Merrimack } \\
\text { Pharmaceuticals }\end{array}$ & HER2 & Phase I & $\begin{array}{l}\text { HER2 Amplified Solid Tumors } \\
\text { Metastatic Breast Cancer }\end{array}$ & Completed & NCT00911898 \\
\hline $\begin{array}{l}\text { MM-111, } \\
\text { Herceptin }\end{array}$ & $\begin{array}{l}\text { Bispecific } \\
\text { antibody fusion } \\
\text { protein }\end{array}$ & $\begin{array}{l}\text { Merrimack } \\
\text { Pharmaceuticals }\end{array}$ & HER2 & Phase I & $\begin{array}{l}\text { Refractory HER } 2 \text { Amplified } \\
\text { Heregulin Positive Breast } \\
\text { Cancer }\end{array}$ & Completed & NCT01097460 \\
\hline ZW25 & $\begin{array}{l}\text { lgG type } \\
\text { bispecific } \\
\text { antibody }\end{array}$ & Zymeworks Inc. & HER2 & Phase I & $\begin{array}{l}\text { Unresectable and/or metastatic } \\
\text { HER2 positive cancers }\end{array}$ & Recruiting & NCT02892123 \\
\hline $\begin{array}{l}\text { Her2 BATs, } \\
\text { Recombinant IL-2 }\end{array}$ & $\begin{array}{l}\text { T cells } \\
\text { preloaded with } \\
\text { lgG type } \\
\text { bispecific } \\
\text { antibody }\end{array}$ & Yi Miao & HER2 & Phase I & $\begin{array}{l}\text { Her2 Positive Neoplasms of } \\
\text { Digestive System }\end{array}$ & Unknown & NCT02662348 \\
\hline MCLA-128 & $\begin{array}{l}\text { lgG type } \\
\text { bispecific } \\
\text { antibody }\end{array}$ & Merus N.V. & $\begin{array}{l}\text { HER2 and } \\
\text { HER3 }\end{array}$ & $\begin{array}{l}\text { Phase I/Phase } \\
\|\end{array}$ & $\begin{array}{l}\text { Malignant solid tumor } \\
\text { Breast cancer } \\
\text { Gastric cancer } \\
\text { Ovarian cancer } \\
\text { Endometrial cancer } \\
\text { Non- Small cell lung cancer }\end{array}$ & Recruiting & NCT02912949 \\
\hline $\begin{array}{l}\text { HER-2 BATs with } \\
\text { Pembrolizumab }\end{array}$ & $\begin{array}{l}\text { T cells } \\
\text { preloaded with } \\
\text { lgG type } \\
\text { bispecific } \\
\text { antibody }\end{array}$ & $\begin{array}{l}\text { University of } \\
\text { Virginia }\end{array}$ & $\begin{array}{l}\text { HER2 } \\
\text { specific } \\
\text { antibody } \\
\text { armed } \\
\text { activated T } \\
\text { cell } \\
\text { infusions }\end{array}$ & $\begin{array}{l}\text { Phase I/Phase } \\
\|\end{array}$ & Metastatic Breast Cancer & Recruiting & NCT03272334 \\
\hline $\begin{array}{l}\text { Anti-CD3 x HER2- } \\
\text { BATs }\end{array}$ & $\begin{array}{l}\text { T cells } \\
\text { preloaded with } \\
\text { IgG type } \\
\text { bispecific } \\
\text { antibody }\end{array}$ & $\begin{array}{l}\text { Barbara Ann } \\
\text { Karmanos Cancer } \\
\text { Institute }\end{array}$ & HER2, CD3 & Phase ॥ & $\begin{array}{l}\text { Metastatic Castration Resistant } \\
\text { Prostate Cancer }\end{array}$ & Recruiting & NCT03406858 \\
\hline GBR1302 & $\begin{array}{l}\text { BEAT-bispecific } \\
\text { antibody with } \\
\text { heavy chain, } \\
\text { light chain and } \\
\text { Fc-scFv }\end{array}$ & $\begin{array}{l}\text { Glenmark } \\
\text { Pharmaceuticals } \\
\text { S.A. }\end{array}$ & HER2, CD3 & Phase I & HER2 Expressing Solid Tumors & Recruiting & NCT02829372 \\
\hline $\begin{array}{l}\text { HER2- BATs, } \\
\text { Pembrolizumab }\end{array}$ & $\begin{array}{l}\text { T cells } \\
\text { preloaded with } \\
\text { lgG type } \\
\text { bispecific } \\
\text { antibody }\end{array}$ & $\begin{array}{l}\text { University of } \\
\text { Virginia }\end{array}$ & $\begin{array}{l}\text { HER2, CD3, } \\
\text { PD-1 }\end{array}$ & $\begin{array}{l}\text { Phase I/ } \\
\text { Phase II }\end{array}$ & Metastatic Breast Cancer & Recruiting & NCT03272334 \\
\hline $\begin{array}{l}\text { MCLA-128/ } \\
\text { trastuzumab/ } \\
\text { chemotherapy, } \\
\text { MCLA-128, endo- } \\
\text { crine therapy }\end{array}$ & $\begin{array}{l}\text { IgG type } \\
\text { bispecific } \\
\text { antibody }\end{array}$ & Merus N.V. & HER2, ER & Phase II & Metastatic Breast Cancer & $\begin{array}{l}\text { Not yet } \\
\text { recruiting }\end{array}$ & NCT03321981 \\
\hline IMCgp100 & TCR fused to & Immunocore Ltd. & HLA A2, & Phase I & Advanced Malignant & Completed & NCT01211262 \\
\hline
\end{tabular}




\section{Radioimmunotherapy}

Radioimmunoscintigraphy (RIS) and radioimmunotherapy (RIT) use the antibody specificity of tumor-based antigens in conjunction with emitted radiation from suitable radioisotopes to image malignancies (RIS) for diagnostic and treatment purposes. The radioantibody is injected intravenously and distributes to the antigen binding site on tumor cells where the radionuclide delivers the tumoricidal dose to the tumor mass (Larson et al. 2015). RIT allows the delivery of radiation doses to multiple dispersed sites simultaneously which makes it effective in killing tumors that have already metastasized to multiple organs (Yang et al. 2016). RIT has traditionally proven efficacious in hematological malignancies such as non-Hodgkin's lymphoma, which are characterized as more radiosensitive than solid tumor malignancies (Song and Sgouros 2011). Solid tumor malignancies require higher radiation doses to induce tumor cell apoptosis leading to increased adverse effects to radiosensitive areas such as the kidney, lung, and bone marrow. However, intra-compartmental RIT, the addition of chemotherapy to RIT, and the use of alpha emitters are being used to improve the therapeutic index of RIT in solid tumors with less toxicity (Larson et al. 2015). One limitation of conventional radioimmunotherapy is the prolonged radiation exposure of nontarget normal tissues and poor tumor to normal tissue radiation absorbed dose ratios. The development of pre-targeted radioimmunotherapy (PRIT), which first allows tumor specific antibodies to distribute to the tumor antigen site followed by the administration of a small radioactive agent with high affinity for the tumor antibody, limits the accumulation of radiation in non-target sites (Larson et al. 2015). Several bispecific antibodies have been designed and used in these capacities as pre-targets for RIT in addition to providing high specificity binding sites for both the tumor antigen and the radioactive material promoting tumor cell death. A trivalent bispecific antibody, TF12, which targets epithelial glycoprotein -1 antigen (EGP-1 or TROP-2) and histaminesuccinyl-glycine (HSG), when used with lutetium-177 labeled peptide for PRIT in prostate cancer demonstrated effective targeting and permeability in mice pre-clinical studies (van Rij et al. 2014). There are many ongoing clinical trials examining the role of bispecific antibodies in RIT for solid tumors eg. colorectal carcinoma [NCT00185081], [NCT02587247], [NCT000860860], HER2 negative breast cancer [NCT01730612], and lung cancer [NCT01221675] (No Title. clinicaltrials.gov n.d.).

\section{Targeting carcino-embryonic antigen (CEA)}

Trials are studying the bi-specific targeting of CD3 in combination with the tumor antigen, CEA, which is highly expressed in gastrointestinal malignances, non-small cell lung cancer (NSCLC), breast cancer, uterine, and bladder cancers [NCT02324257], [NCT01284231] (No Title. clinicaltrials.gov n.d.). CEA is also used as a target in the DNL TF2 antibody which divalently binds CEA and monovalently binds the peptide-hapten histamine-succinyl-glycine (HSG). Similar to the TF12 format described above, the TF2 antibody first binds to CEA, then an HSG peptide carrying a radionuclide is given which can be used for imaging of the tumor or to deliver radiation to the tumor cells [NCT00895323], [NCT01730612], [NCT01221675] (No Title. clinicaltrials.gov n.d.). In a recent study comparing pre-targeted immunoPET, which uses TF2 and Ga-IMP-288, to conventional ${ }^{18}$ FDG PET, immunoPET was more sensitive than ${ }^{18}$ FDG PET (67\% versus $31 \%$ ) for detection of colonic liver lesions in an orthotopic murine model (Foubert et al. 2018).

\section{Targeting MET and EGFR}

The receptor tyrosine kinase, MET, is one of the most commonly dysregulated oncogenes in non-small cell lung cancer (NSCLC) and met gene amplification has been shown to be a major mechanism in which cancers develop resistance to EGFR inhibitors (Bean et al. 2007). Phase III studies which solely targeted MET have failed to show clinical benefit in NSCLC (Baldacci et al. 2017) but dual targeting of MET and EGFR using bispecific antibodies is promising (Tang et al. 2008; Castoldi et al. 2013) and is currently being explored in NSCLC [NCT02609776] (No Title. clinicaltrials.gov n.d.) and other solid tumors [NCT02221882] (No Title. clinicaltrials.gov n.d.). However, other studies such as the MEHGAN study have provided definitive clinical evidence refuting this hypothesis (Fayette et al. 2016).

EGFRvIII, a rearranged variant of EGFR frequently expressed and associated with poor prognosis in Glioblastoma Multiforme (GBM), and also found in breast and lung carcinoma, was recently found to be expressed in glioma stem cell lines (Emlet et al. 2014). In vivo, a bi-scFv binding CD3 and EGFRvIII, has shown efficacy, specificity, and potency in mice with established EGFRvIII intra-cerebral tumors and may be promising in this highly fatal and difficult to treat malignancy (Gedeon et al. 2013). Another novel method of targeting EGFR, designed by Engeneic, are bacteria derived nanocells coated with bispecific antibodies which can be packaged with chemotherapy such as doxorubicin or mRNA. The bispecific antibody coating allows specificity to certain tumor antigens such as EGFR and limits toxicity to normal cells. The chemotherapy or mRNA payload is released directly into the tumor cell increasing the potency of the therapeutic agent (Shah et al. 2016). There are several phase I trials examining the efficacy of these molecules in EGFR positive CNS tumors as well as solid 
Table 4 Recent clinical trials involving the use of bispecific antibodies in solid tumor malignancies (Continued)

\begin{tabular}{|c|c|c|c|c|c|c|c|}
\hline Drug name & Antibody type & Sponsor & $\begin{array}{l}\text { Target } \\
\text { antigens }\end{array}$ & $\begin{array}{l}\text { Development } \\
\text { stage }\end{array}$ & Indication & Status & $\begin{array}{l}\text { Clinical trials } \\
\text { identifier }\end{array}$ \\
\hline & ScFv & & CD3 & & Melanoma & & \\
\hline FS118 & $\begin{array}{l}\text { IgG type } \\
\text { bispecific } \\
\text { antibody with } \\
\text { Fc capable of } \\
\text { antigen binding }\end{array}$ & $\begin{array}{l}\text { F-star Delta } \\
\text { Limited }\end{array}$ & $\begin{array}{l}\text { LAG3, PD- } \\
\text { L1 }\end{array}$ & Phase I & Advanced Malignancies & Recruiting & NCT03440437 \\
\hline LY3164530 & $\begin{array}{l}\text { lgG4 antibody } \\
\text { combined with } \\
\text { scFV }\end{array}$ & $\begin{array}{l}\text { Eli Lilly and } \\
\text { Company }\end{array}$ & $\begin{array}{l}\text { MET and } \\
\text { Anti- EGFR }\end{array}$ & Phase I & $\begin{array}{l}\text { Metastatic neoplasm including } \\
\text { NSCLC }\end{array}$ & Completed & NCT02221882 \\
\hline $\begin{array}{l}\text { Anti-CD3-MUC1 } \\
\text { and Activated CIK }\end{array}$ & $\begin{array}{l}\text { Fusion of two } \\
\text { Fab fragments }\end{array}$ & $\begin{array}{l}\text { Benhealth } \\
\text { Biopharmaceutical } \\
\text { (Shenzhen) Co., } \\
\text { Ltd }\end{array}$ & $\mathrm{MUC1}, \mathrm{CD} 3$ & Phase II & Advanced liver cancer & Recruiting & NCT03146637 \\
\hline $\begin{array}{l}\text { Activated CIK with } \\
\text { CD3-MUC1 }\end{array}$ & $\begin{array}{l}\text { Fusion of two } \\
\text { Fab fragments }\end{array}$ & $\begin{array}{l}\text { Fuda Cancer } \\
\text { Hospital, } \\
\text { Guangzhou }\end{array}$ & MUC1, CD3 & Phase II & Advanced liver cancer & Recruiting & NCT03484962 \\
\hline $\begin{array}{l}\text { Activated CIK with } \\
\text { CD3-MUC1 }\end{array}$ & $\begin{array}{l}\text { Fusion of two } \\
\text { Fab fragments }\end{array}$ & $\begin{array}{l}\text { Fuda Cancer } \\
\text { Hospital, } \\
\text { Guangzhou }\end{array}$ & MUC1, CD3 & Phase II & Advanced gastric cancer & Recruiting & NCT03554395 \\
\hline $\begin{array}{l}\text { Activated CIK with } \\
\text { CD3-MUC1 }\end{array}$ & $\begin{array}{l}\text { Fusion of two } \\
\text { Fab fragments }\end{array}$ & $\begin{array}{l}\text { Fuda Cancer } \\
\text { Hospital, } \\
\text { Guangzhou }\end{array}$ & $\mathrm{MUC1}, \mathrm{CD} 3$ & Phase II & Advanced kidney cancer & Recruiting & NCT03540199 \\
\hline $\begin{array}{l}\text { Activated CIK with } \\
\text { CD3- MUC1 }\end{array}$ & $\begin{array}{l}\text { Fusion of two } \\
\text { Fab fragments }\end{array}$ & $\begin{array}{l}\text { Fuda Cancer } \\
\text { Hospital, } \\
\text { Guangzhou }\end{array}$ & $\mathrm{MUC1}, \mathrm{CD} 3$ & Phase II & Advanced breast cancer & Recruiting & NCT03524261 \\
\hline $\begin{array}{l}\text { Activated CIK with } \\
\text { CD3- MUC1 }\end{array}$ & $\begin{array}{l}\text { Fusion of two } \\
\text { Fab fragments }\end{array}$ & $\begin{array}{l}\text { Fuda Cancer } \\
\text { Hospital, } \\
\text { Guangzhou }\end{array}$ & $\mathrm{MUC1}, \mathrm{CD} 3$ & Phase II & Advanced lung cancer & Recruiting & NCT03501056 \\
\hline $\begin{array}{l}\text { Activated CIK with } \\
\text { CD3-MUC1 }\end{array}$ & $\begin{array}{l}\text { Fusion of two } \\
\text { Fab fragments }\end{array}$ & $\begin{array}{l}\text { Fuda Cancer } \\
\text { Hospital, } \\
\text { Guangzhou }\end{array}$ & MUC1, CD3 & Phase II & Advanced colorectal cancer & Recruiting & NCT03524274 \\
\hline $\begin{array}{l}\text { Activated CIK with } \\
\text { CD3-MUC1 }\end{array}$ & $\begin{array}{l}\text { Fusion of two } \\
\text { Fab fragments }\end{array}$ & $\begin{array}{l}\text { Fuda Cancer } \\
\text { Hospital, } \\
\text { Guangzhou }\end{array}$ & MUC1, CD3 & Phase II & Advanced pancreatic cancer & Recruiting & NCT03509298 \\
\hline PF-06671008 & DART & Pfizer & $\begin{array}{l}\text { P-Cadherin, } \\
\text { CD3 }\end{array}$ & Phase I & Advanced Solid Tumors & Recruiting & NCT02659631 \\
\hline XmAb20717 & $\begin{array}{l}\text { Fc engineered } \\
\text { bispecific } \\
\text { antibody }\end{array}$ & Xencor & PD1, CTLA4 & Phase I & $\begin{array}{l}\text { Selected Advanced Solid } \\
\text { Tumors }\end{array}$ & Recruiting & NCT03517488 \\
\hline MGD013 & DART & MacroGenics & $\begin{array}{l}\text { PDL-1, } \\
\text { LAG-3 }\end{array}$ & Phase I & $\begin{array}{l}\text { Unresectable or Metastatic } \\
\text { Neoplasm }\end{array}$ & Recruiting & NCT03219268 \\
\hline ES414 & $\begin{array}{l}\text { scFv domains } \\
\text { linked to Fc of } \\
\operatorname{lgG1}\end{array}$ & $\begin{array}{l}\text { Aptevo } \\
\text { Therapeutics }\end{array}$ & PSMA, CD3 & Phase I & $\begin{array}{l}\text { Metastatic Castration Resistant } \\
\text { Prostate Cancer }\end{array}$ & Recruiting & NCT02262910 \\
\hline BAY2010112 & BITE & Bayer & PSMA, CD3 & Phase I & $\begin{array}{l}\text { Castration Resistant Prostate } \\
\text { Cancer }\end{array}$ & $\begin{array}{l}\text { Active, not } \\
\text { recruiting }\end{array}$ & NCT01723475 \\
\hline XmAb18087 & $\begin{array}{l}\text { Fc engineered } \\
\text { bispecific } \\
\text { antibody }\end{array}$ & Xencor & SSTR2, CD3 & Phase I & $\begin{array}{l}\text { Advanced Neuroendocrine } \\
\text { Tumor and Gastrointestinal } \\
\text { Stromal Tumors }\end{array}$ & Recruiting & NCT03411915 \\
\hline
\end{tabular}

tumors [NCT02766699, NCT02687386] (No Title. clinicaltrials.gov n.d.).

\section{Targeting EpCAM}

In addition to catumaxomab described above, many other molecules targeting EpCAM have been explored in clinical trials. In vitro studies showed that Solitomab (MT110), which binds CD3 and targets EpCAM, increased the sensitivity of tumor cells to cytotoxic $\mathrm{T}$ cell death in multiple EpCAM positive ovarian and endometrial cancer cell lines including ovarian carcinosarcoma and primary uterine serous papillary carcinoma (Bellone 
et al. 2016; English et al. 2014). An open- label multi-center dose escalation phase I study was completed in 2015 but the results have not yet been published [NCT00635596] (No Title. clinicaltrials.gov n.d.).

\section{Targeting the HER 2}

Ertumaxomab, a trifunctional bispecific targeting HER/ neu, CD3, and Fc receptors showed radiographically confirmed clinical response and safety in phase I trials with metastatic breast cancer patients and promising early results of phase II (Haense et al. 2016; View et al. 2008). The phase II clinical trial however was terminated by the sponsor for financial reasons. A phase I/II trial is currently recruiting patients to study the potential effects of MCLA-128 which bi-specifically targets HER2 and HER3 in HER 2 positive breast cancer and other malignant solid tumors [NCT02912949] (No Title. clinicaltrials.gov n.d.). Another phase I trial is evaluating the bispecific targeting of the extracellular domain of HER 2 in HER 2 positive breast cancer with the humanized antibody ZW25 [NCT02892123] (No Title. clinicaltrials.gov n.d.). While HER2 has already proven to be an effective target in breast cancer, preclinical studies have suggested that targeting HER2 and CD3 T cells in metastatic castrate resistant prostate cancer might be an effective strategy (Vaishampayan et al. 2015).

\section{Targeting Mucin-1 (MUC-1)}

Muc-1 is a membrane protein found on the surface of many adenocarcinomas and plays a role in inhibiting the p53 tumor suppression gene (Wei et al. 2007; Kwak et al. 2010). Previously monoclonal antibody therapy directed at MUC-1 from normal tissues was ineffective but recent advancements in targeting tumor Muc1 has been promising in monoclonal antibody studies and CAR-T cell directed therapy (Danielczyk et al. 2006; Posey et al. 2016). Bispecific targeting of MUC-1 and CD16 to mediate NK cytotoxicity cells to target tumor cells in xenograft models has shown effective tumor suppression (Li et al. 2018). A novel PD-1 inhibitor induced cytokine- induced killer cells (CIKs) mixed with an anti-MUC 1 and anti- CD3 bispecific antibody is currently being investigated in several clinical trials for the treatment of advanced solid tumor malignancies [NCT03540199], [NCT03524261], [NCT03501056], NCT03524274], [NCT03509298] (No Title. clinicaltrials.gov n.d.). The bispecific antibody binds to CD3 on the CIK and MUC1 on tumor cells, crosslinking the CIKs and tumor cells promoting effective tumor cell lysis.

Targeting the prostate-specific membrane antigen (PSMA) PSMA expressed predominantly in prostate cancer cells as well as the neovasculature of most solid tumors has been a common target in prostate cancer patients (Rajasekaran 2005). A bispecific diabody targeting PSMA in conjunction with antibodies against CD3 has decreased prostate specific antigen levels, inhibited tumor growth and prolonged survival in preclinical mouse studies (Bühler et al. 2008).

\section{Targeting the immune checkpoint molecules}

An interesting strategy of simultaneous blockade of immune checkpoint molecules such as cytotoxic T-lymphocyte antigen-4 (CTLA4) or programmed death-1 (PD-1) or its ligand (PD-L1) and transforming growth factor- $\beta$ (TGF- $\beta$ ), which mediates immune tolerance using a bifunctional antibody-ligand trap was recently reported (Ravi et al. 2018). One such novel DART bispecific antibody, FS118, which simultaneously inhibits two checkpoint molecules, PDL-1 and lymphocyte activation gene 3 protein (LAG3) is currently in phase I trial in patients with advanced solid tumor malignancies [NCT03440437] (No Title. clinicaltrials.gov n.d.). These agents may potentially improve the efficacy of checkpoint inhibition in various solid tumors which has traditionally been limited with monotherapy.

\section{Bi and tri-specific $\mathrm{T}$ cell and natural killer cell engagers} Innovative techniques to harness natural killer cell in immunotherapy have introduced the concept of bi-specific killer cell engagers (BiKEs) and tri-specific killer cell engagers (TriKEs). BiKEs are created by the fusion of a single chain variable fragment $(\mathrm{Fv})$ against $\mathrm{CD}$ 16 (antigen on natural killer cells) and a single-chain Fv against a tumor associated antigen (Rezvani and Rouce 2015). TriKEs are a combination of a single-chain $\mathrm{Fv}$ against CD16 and two tumor associated antigens. These molecules directly trigger NK cell activation through CD 16 amplifying NK cell cytolytic activity and cytokine production against various tumor cell antigen targets (Gleason et al. 2012). These drugs are currently being investigated in preclinical studies and safety remains a concern with the potential to trigger cytokine cascades (Tay et al. 2016).

\section{Targeting other tumor associated antigens}

Other tumor-associated antigens that have been studied in monoclonal antibody directed therapy are currently being investigated for bi-specific therapy. Some of these promising target antigens are not just tumor markers but molecules found to be essential in tumor cell survival and proliferation. For example, a bi-specific antibody that targets melanoma- associated chondroitin sulfate proteoglycan (MCSP) and targets the death receptor 5 (DR5, TRAIL-R2), can selectively and potently kill melanoma cells. This approach may prove beneficial in those patients resistant to monoclonal antibody 
therapy (He et al. 2016). rM28, a single chain bispecific format also targeting a melanoma associated proteoglycan recombinant, in addition to targeting CD28, a co-stimulatory molecule on $\mathrm{T}$ cells, showed tumor cell killing without the need for additional TCR/ CD3 stimulation (Grosse-Hovest et al. 2003). P- Cadherin, a cell-to cell adhesion molecule, is upregulated in various solid tumors and overexpression is associated with poor prognosis in breast, ovarian, endometrial, colorectal cancers, intrahepatic cholangiocarcinoma, and pancreatic cancer. Pre-clinical studies of DART antibodies targeting PCadherin and CD3 showed significant regression of solid tumors in vitro and in vivo in mice (Fisher et al. 2018). Pfizer is currently conducting a dose escalation study of this molecule, PF-06671008, in patients with P-Cadherin expressing NSCLC, CRC, and triple negative breast cancer (TNBC) [NCT02659631] (No Title. clinicaltrials.gov n.d.). Vascular endothelial growth factor (VEGF) and Angiopoietin-2 (Ang-2), both essential in tumor angiogenesis and escape, are being studied in various combination bispecific formats [NCT03035253], [NCT03292783], [NCT02665416], NCT03030287] (No Title. clinicaltrials.gov n.d.).

\section{Simultaneous targeting of multiple antigens}

Even though most polyspecific antibodies have two binding sites (bispecific), there are many new molecules with three or four binding sites. For example, Castoldi et al., have recently developed a tetravalent Fc containing antibody (tetramab) directed against HER1, HER3, c-MET and IGF1R with enhanced antitumor effects in a preclinical model (Castoldi et al. 2016).

\section{Other novel applications of PsMab therapy}

Another example of how novel approaches may simplify treatment is a recent preclinical study demonstrating elimination of large tumors by in-vivo production of bispecific antibodies induced by parenterally administered engineered mRNA (Holzinger et al. 2016). If applicable to humans, the high cost of immunotherapy could be dropped to levels of more traditional agents. Another intriguing approach to enhance antitumor effect is the use of a tri-specific antibody with an IL-15 cross linker causing enhanced NK activity antitumor activity (Schmohl et al. 2016). If the construct turns out to be non- immunogenic and has enough drug like properties to allow it to advance in development, the agent may offer an attractive treatment for appropriate tumors. The structure of a typical tri-specific antibody is shown in (Fig. 3).

\section{Chimeric antigen receptor adoptive $T$ cell therapy (CAR-T)}

Advances in antibody directed therapy have simultaneously fostered the development of another form of

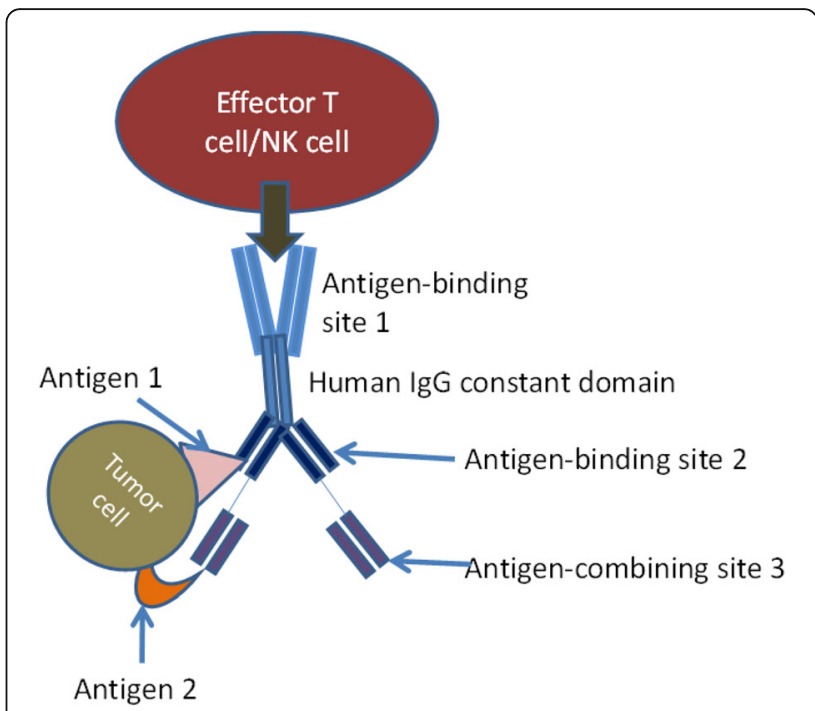

Fig. 3 Trispecific antibody. Usually created by using variable domain genes if specific monoclonal antibodies. In this case, antigen-binding site 1 is bivalent and engages with an antigen on effector cell, antigen-binding sites 2 and 3 engage antigens 1 and 2 on tumor cells

immunotherapy, CAR-T cell therapy. While an in-depth discussion on this exciting topic is out of scope for this review article which is focused on polyspecific antibodies, we present a brief review on the topic here and compare the two forms of immunotherapy. CAR-T cell therapy consists on removing $\mathrm{T}$ cells from patients and modifying ex vivo using gene transfer to enable expression of specific receptors targeting tumor cells through an antibody-derived binding domain. Once the $\mathrm{T}$ cells are genetically modified to express the chimeric antigen receptor, they are infused back into the patients to directly kill the cancer cells (Fig. 2) (Caruana et al. 2014). Currently, CAR T-cell therapy has demonstrated significant anti-tumor activity in the treatment of hematological malignancies. Tisagenlecleucel, CAR T-cell therapy directed at CD19 B- cells, was FDA approved in August 2017 for treatment of pediatric patients with refractory or relapsed B-cell precursor acute lymphoblastic leukemia (Mullard 2017). Multiple CAR-T agents are currently in advanced stages of clinical development for various hematological malignancies (Gauthier and Yakoub-Agha 2017). In contrast, the success of CAR T-cell therapy in solid tumors however has been limited due to the complex tumor microenvironment and difficulty finding suitable target antigens (Gauthier and Yakoub-Agha 2017; Zeltsman et al. 2017). Toxicity and cost have also been major issues with CAR-T cell therapy that are being actively discussed in various forums (Gauthier and Yakoub-Agha 2017; Abbasi 2017). Polyspecific antibodies may offer advantages over CAR-T cell therapy in a multitude of ways and the major 
differences between the two strategies are tabulated in (Table 5).

While both monoclonal antibody therapy and CAR $\mathrm{T}$-cells are antigen specific immunotherapies, CAR $\mathrm{T}$ cells, at present, have to be individually manufactured for each patient resulting in high cost of production. Despite this, CAR T-cells exhibit several qualities that could make them more advantageous than antibody directed tumor therapy. The genetically engineered receptors allow CAR T-cells to recognize tumor cells with low antigen expression and cause direct lysis of tumor cells whereas classical monoclonal antibodies need a high density of tumor antigens to trigger the ADCC or complement cascade (Caruana et al. 2014; Gauthier and Yakoub-Agha 2017). The new constructs of polyspecific antibodies also allow enhanced binding to target and in preclinical models have significantly enhanced anticancer activity compared to monoclonal antibodies (Mazor et al. 2017). Another significant advantage of CAR-T cells therapy is that $\mathrm{T}$ cells can naturally extravasate and travel between endothelial barriers within tissue, unlike monoclonal antibodies, which are limited by their size. While the older bispecific constructs have the same disadvantage as mAbs, the newer formats can be made smaller than a classical immunoglobulin allowing better distribution but then usually have a reduced plasma half-life (Brinkmann and Kontermann 2017). In terms of duration of activity, limited data on genetically engineered CAR-T cells suggest that these cells may be able to expand in vivo and result in prolonged response to treatment if a memory pool is established (Caruana et al. 2014). Whether this is a long term advantage is unclear as tumor recurrence lacking the target epitope has been

Table 5 Comparing bi-specific and tri-specific antibody therapy to CAR T- cell therapy

\begin{tabular}{|c|c|}
\hline Polyspecific antibodies & CAR T- cells \\
\hline $\begin{array}{l}\text { Polyspecific are antibodies with } \\
\text { multiple specificities with one or } \\
\text { more affinity sites towards tumor } \\
\text { antigens, and another one towards } \\
\text { an activator on immune effectors } \\
\text { (e.g. CD3 on T cells). }\end{array}$ & $\begin{array}{l}\text { T cells with genetically engineered } \\
\text { receptors that redirect them to a } \\
\text { chosen tumor antigen }\end{array}$ \\
\hline $\begin{array}{l}\text { Highly efficient, rapid process- } \\
\text { Created using multiple formats } \\
\text { including advanced protein } \\
\text { engineering and recombinant DNA } \\
\text { technologies and administered to } \\
\text { patients directly. Allows rapid } \\
\text { treatment of patients }\end{array}$ & $\begin{array}{l}\text { Cumbersome, boutique process- T } \\
\text { cells from patients are collected, } \\
\text { antigen specific receptors (CARs) } \\
\text { are inserted invitro into T cells } \\
\text { using viral vectors, DNA } \\
\text { transposons, or RNA transfection } \\
\text { and then "expanded" in the } \\
\text { laboratory before reinfusing into } \\
\text { lyphodepleted patient. May delay } \\
\text { therapy for weeks. }\end{array}$ \\
\hline $\begin{array}{l}\text { When activated through CD3, } \\
\text { cytotoxic T cells inject perforin and } \\
\text { granzyme B into target cells to kill. }\end{array}$ & $\begin{array}{l}\text { When CARs bind to tumor antigen, } \\
\text { the intracellular signaling domain } \\
\text { is activated and the tumoricidal } \\
\text { process by } T \text { cells is initiated. }\end{array}$ \\
\hline
\end{tabular}

noted in hematological studies. On the contrary, the short half-life of most engineered antibodies necessitates multiple doses to ensure effective therapy but this has been also improvised in some of the newer constructs by adding a FC component or chemically modifying the molecule.

\section{Conclusions}

Antibody-based cancer directed therapy is an exciting and rapidly advancing field. The introduction of monoclonal antibodies such as rituximab revolutionized cancer therapy and have given way to the creation of bi-specific and tri-specific antibodies which work with more precision and efficacy than their predecessors. The one currently approved bi-specific antibody therapy, blinatumomab and catumaxomab, have shown improved survival rates and quality of life for subsets of cancer patients. Multiple agents are currently being evaluated in clinical trials while optimal structures and treatment algorithms are being defined to maximize benefit-risk ratio. Newer approaches concurrently targeting checkpoint molecules and cancer-specific antigens seem promising in preclinical models and may change the landscape of cancer therapeutics (Junttila et al. 2014; Hong et al. 2018).

Several biological parameters are still missing in the understanding of the tumor biology and its complex microenvironment. Engineered polyspecific antibodies will likely play a major role in oncotherapeutics as cancer research continues to climb to new heights.

\section{Abbreviations \\ ADCC: Antibody-Dependent Cell-mediated Cytotoxicity; CA: Cancer Antigen; CAR: Chimeric Antigen Receptor; CD: Cluster of Differentiation; \\ CEA: CarcinoEmbryonic Antigen; DNA: Deoxyribonucleic Acid; DR: Death Receptor; EGF: Epidermal Growth Factor; EGFR: Epidermal Growth Factor Receptor; FC: Fragment Crystallizable; FDA: Food and Drug Administration; HER: Human Epithelial Growth Factor Receptor; HLA: Human Leukocyte Antigen; IGF1R: Insulin Growth Factor 1 Receptor; IL: InterLeukin; MET: Mesenchymal-Epithelial Transition factor; mRNA: Messenger Ribonucleic Acid; NCT: National Clinical Trial; NK: Natural Killer; TRAIL-R: Tumor Necrosis Factor-Related Apoptosis-inducing Ligand Receptors \\ Funding \\ Detailed in the funding section.}

\section{Availability of data and materials}

All references alluded to in the text are listed along with available identifiers in the 'references section'. Ongoing clinical trials were obtained through clinicaltrials.gov and listed by their NCT number.

\section{Authors' contributions}

All authors have contributed equally to this manuscript. All authors have read and approved the final manuscript.

\section{Ethics approval and consent to participate}

Not applicable.

Consent for publication

Not applicable.

Competing interests

The authors declare that they have no competing interests. 


\section{Publisher's Note}

Springer Nature remains neutral with regard to jurisdictional claims in published maps and institutional affiliations.

Received: 16 April 2018 Accepted: 10 September 2018

Published online: 24 September 2018

\section{References}

Abbasi J. Amid FDA approval filings, another CAR-T therapy patient death. JAMA. 2017;317:2271.

Baldacci S, Mazieres J, Tomasini P, et al. Outcome of EGFR-mutated NSCLC patients with MET-driven resistance to EGFR tyrosine kinase inhibitors. Oncotarget. 2017:8:105103-14. https://doi.org/10.18632/oncotarget.21707.

Baumann K, Pfisterer J, Wimberger $\mathrm{P}$, et al. Intraperitoneal treatment with the trifunctional bispecific antibody Catumaxomab in patients with platinumresistant epithelial ovarian cancer: a phase lla study of the AGO study group. Gynecol Oncol. 2011;123:27-32. https://doi.org/10.1016/j.ygyno.2011.06.004.

Bean J, Brennan C, Shih J-Y, et al. MET amplification occurs with or without T790M mutations in EGFR mutant lung tumors with acquired resistance to gefitinib or erlotinib. Proc Natl Acad Sci. 2007;104:20932-7. https://doi.org/10. 1073/pnas.0710370104.

Bellone S, Black J, English DP, et al. Solitomab, an EpCAM/CD3 bispecific antibody construct (BiTE), is highly active against primary uterine serous papillary carcinoma cell lines in vitro. Am J Obstet Gynecol. 2016;214:99.e1-8. https:// doi.org/10.1016/j.ajog.2015.08.011.

Binyamin L, Borghaei $\mathrm{H}$, Weiner LM. Cancer therapy with engineered monoclonal antibodies. Update Cancer Ther. 2006;1:147-57.

Brinkmann U, Kontermann RE. The making of bispecific antibodies. MAbs. 2017;9: $182-212$.

Bühler $\mathrm{P}$, Wolf $\mathrm{P}$, Gierschner $\mathrm{D}$, et al. A bispecific diabody directed against prostate-specific membrane antigen and CD3 induces T-cell mediated lysis of prostate cancer cells. Cancer Immunol Immunother. 2008;57:43-52. https://doi.org/10.1007/s00262-007-0348-6.

Caruana I, Diaconu I, Dotti G. From monoclonal antibodies to chimeric antigen receptors for the treatment of human malignancies. Semin Oncol. 2014;41: 661-6.

Castoldi R, Ecker V, Wiehle $L$, et al. A novel bispecific EGFR/met antibody blocks tumor-promoting phenotypic effects induced by resistance to EGFR inhibition and has potent antitumor activity. Oncogene. 2013:32:5593-601. https://doi.org/10.1038/onc.2013.245.

Castoldi R, Schanzer J, Panke C, et al. TetraMabs: simultaneous targeting of four oncogenic receptor tyrosine kinases for tumor growth inhibition in heterogeneous tumor cell populations. Protein Eng Des Sel. 2016;29:467-75. https://doi.org/10.1093/protein/gzw037.

Danielczyk A, Stahn R, Faulstich D, et al. PankoMab: a potent new generation anti-tumour MUC1 antibody. Cancer Immunol Immunother. 2006:55:1337-47. https://doi.org/10.1007/s00262-006-0135-9.

Emlet DR, Gupta P, Holgado-Madruga M, et al. Targeting a glioblastoma cancer stem-cell population defined by EGF receptor variant III. Cancer Res. 2014;74: 1238-49. https://doi.org/10.1158/0008-5472.CAN-13-1407.

English DP, Bellone S, Schwab CL, et al. Solitomab, an epithelial cell adhesion molecule/CD3 bispecific antibody (BiTE), is highly active against primary chemotherapy-resistant ovarian cancer cell lines in vitro and fresh tumor cells ex vivo. Cancer. 2014;121(3):403-12. https://doi.org/10.1002/cncr.29062.

Fan G, Wang Z, Hao M, Li J. Bispecific antibodies and their applications. J Hematol Oncol. 2015;8:130. https://doi.org/10.1186/s13045-015-0227-0.

Fayette J, Wirth L, Oprean C, et al. Randomized phase II study of Duligotuzumab (MEHD7945A) vs. Cetuximab in squamous cell carcinoma of the head and neck (MEHGAN study). Front Oncol. 2016;6:232. https://doi.org/10.3389/fonc. 2016.00232.

Fisher TS, Hooper AT, Lucas J, et al. A CD3-bispecific molecule targeting Pcadherin demonstrates $T$ cell-mediated regression of established solid tumors in mice. Cancer Immunol Immunother. 2018:67:247-59. https://doi. org/10.1007/s00262-017-2081-0.

Foubert F, Gourard S, Sai-Maurel C, Cherel M, faivre-Chauvet A, Gldenberg D. No Title. Oncotarget. 2018;9:27502-13.

Fousek K, Ahmed N. The evolution of T-cell therapies for solid malignancies. Clin Cancer Res. 2015;21:3384-92.

Frampton JE. Catumaxomab: In malignant ascites. Drugs. 2012:72:1399-410. https://doi.org/10.2165/11209040-000000000-00000.
Gauthier J, Yakoub-Agha I. Chimeric antigen-receptor T-cell therapy for hematological malignancies and solid tumors: clinical data to date, current limitations and perspectives. Curr Res Transl Med. 2017;65:93-102.

Gedeon PC, Choi BD, Hodges TR, et al. An EGFRvlll-targeted bispecific T-cell engager overcomes limitations of the standard of care for glioblastoma. Expert Rev Clin Pharmacol. 2013;6:375-86.

Gleason MK, Verneris MR, Todhunter DA, et al. Bispecific and Trispecific killer cell engagers directly activate human NK cells through CD16 signaling and induce cytotoxicity and cytokine production. Mol Cancer Ther. 2012;11:267484. https://doi.org/10.1158/1535-7163.MCT-12-0692.

Grosse-Hovest L, Hartlapp I, Marwan W, et al. A recombinant bispecific singlechain antibody induces targeted, supra-agonistic CD28-stimulation and tumor cell killing. Eur J Immunol. 2003;33:1334-40. https://doi.org/10.1002/eji. 200323322.

Haense N, Atmaca A, Pauligk C, et al. A phase I trial of the trifunctional anti Her2 $\times$ anti CD3 antibody ertumaxomab in patients with advanced solid tumors. BMC Cancer. 2016;16:420. https://doi.org/10.1186/s12885-016-2449-0.

He Y, Hendriks D, van Ginkel R, et al. Melanoma-directed activation of apoptosis using a bispecific antibody directed at MCSP and TRAIL Receptor-2/death Receptor-5. J Invest Dermatol. 2016;136:541-4. https://doi.org/10.1016/j.jid.2015.11.009.

Heiss MM, Murawa $P$, Koralewski $P$, et al. The trifunctional antibody catumaxomab for the treatment of malignant ascites due to epithelial cancer: results of a prospective randomized phase II/III trial. Int J Cancer. 2010;127:2209-21. https://doi.org/10.1002/ijc.25423.

Henricks LM, Schellens JH, Huitema AD, Beijnen JH. The use of combinations of monoclonal antibodies in clinical oncology. Cancer Treat Rev. 2015;41:85967. https://doi.org/10.1016/j.ctrv.2015.10.008.

Holliger P, Winter G. Engineering bispecific antibodies. Curr Opin Biotechnol. 1993:4:446-9. https://doi.org/10.1016/0958-1669(93)90010-T.

Holzinger A, Barden M, Abken $\mathrm{H}$. The growing world of CAR T cell trials: a systematic review. Cancer Immunol Immunother. 2016;65:1433-50.

Hong R, Zhou Y, Tian X, et al. Selective inhibition of IDO1, D-1-methyl-tryptophan (D-1MT), effectively increased EpCAM/CD3-bispecific BiTE antibody MT110 efficacy against IDO1hibreast cancer via enhancing immune cells activity. Int Immunopharmacol. 2018;54:118-24. https://doi.org/10.1016/j.intimp.2017.10.008.

Junttila TT, Li J, Johnston J, et al. Antitumor efficacy of a bispecific antibody that targets HER2 and activates T cells. Cancer Res. 2014;74:5561-71. https://doi. org/10.1158/0008-5472.CAN-13-3622-T.

Kalyankrishna S, Grandis JR. Epidermal growth factor receptor biology in head and neck cancer. J Clin Oncol. 2006;24:2666-72. https://doi.org/10.1200/JCO. 2005.04.8306.

Kantarjian H, Stein A, Gökbuget N, et al. Blinatumomab versus chemotherapy for advanced acute lymphoblastic leukemia. N Engl J Med. 2017;376:836-47. https://doi.org/10.1056/NEJMoa1609783.

Karpovsky B, Titus JA, Stephany DA, Segal DM. Production of target-specific effector cells using hetero-cross-linked aggregates containing anti-target cell and anti-Fc gamma receptor antibodies. J Exp Med. 1984;160:1686-701. https://doi.org/10.1084/jem.160.6.1686.

Kontermann RE. Dual targeting strategies with bispecific antibodies. MAbs. 2012;4: 182-97.

Kurbacher CM, Horn O, Kurbacher JA, et al. Outpatient intraperitoneal Catumaxomab therapy for malignant ascites related to advanced gynecologic neoplasms. Oncologist. 2015;20:1333-41. https://doi.org/10. 1634/theoncologist.2015-0076.

Kwak EL, Bang Y-J, Camidge DR, et al (2010) Anaplastic lymphoma kinase inhibition in non-small-cell lung cancer.

Larson SM, Carrasquillo JA, Cheung NKV, Press OW. Radioimmunotherapy of human tumours. Nat Rev Cancer. 2015;15:347-60.

Leget GA, Czuczman MS. Use of rituximab, the new FDA-approved antibody. Curr Opin Oncol. 1998:10:548-51.

Li Y, Zhou C, Li J, et al. Single domain based bispecific antibody, Muc1-Bi-1, and its humanized form, Muc1-bi-2, induce potent cancer cell killing in muc1 positive tumor cells. PLoS One. 2018;13:e0191024. https://doi.org/10.1371/ journal.pone.0191024.

Linke R, Klein A, Seimetz D. Catumaxomab: clinical development and future directions. MAbs. 2010;2:129-36. https://doi.org/10.4161/mabs.2.2.11221.

Loibl S, Gianni L. HER2-positive breast cancer. Lancet. 2017;389:2415-29.

Mandikian D, Takahashi N, Lo AA, et al. Relative Target Affinities of T CellDependent Bispecific Antibodies Determine Biodistribution in a Solid Tumor Mouse Model. Mol Cancer Ther. 2018, 2017. https://doi.org/10.1158/15357163.MCT-17-0657. 
Mazor Y, Sachsenmeier KF, Yang C, et al. Enhanced tumor-targeting selectivity by modulating bispecific antibody binding affinity and format valence. Sci Rep. 2017;7:40098. https://doi.org/10.1038/srep40098.

Mertens N, Schoonjans R, Willems A, et al (2001) New recombinant bi- and trispecific antibody derivatives. Novel Frontiers in the Production of Compounds for Biomedical Use, Vol 1 1:195-208 . doi: https://doi.org/10. 1007/0-306-46885-9_12.

Mullard A. FDA approves first CAR T therapy. Nat Rev Drug Discov. 2017;16:669.

Newman MJ, Benani DJ. A review of blinatumomab, a novel immunotherapy. J Oncol Pharm Pract. 2016;22:639-45. https://doi.org/10.1177/ 1078155215618770

Nisonoff A, Rivers MM. Recombination of a mixture of univalent antibody fragments of different specificity. Arch Biochem Biophys. 1961;93:460-2.

No Title. https://neovii.com/neovii-completes-marketing-authorisationwithdrawal-of-removab-in-the-european-union/. Accessed 5 July 2018.

No Title. https://clinicaltrials.gov/. Accessed 20 July 2018.

Offner S, Hofmeister R, Romaniuk A, et al. Induction of regular cytolytic T cell synapses by bispecific single-chain antibody constructs on MHC class Inegative tumor cells. Mol Immunol. 2006;43:763-71. https://doi.org/10.1016/j. molimm.2005.03.007.

Ooi A, Takehana T, Li X, et al. Protein overexpression and gene amplification of HER-2 and EGFR in colorectal cancers: an immunohistochemical and fluorescent in situ hybridization study. Mod Pathol. 2004;17:895-904. https:// doi.org/10.1038/modpathol.3800137.

Perez P, Hoffman RW, Shaw S, et al. Specific targeting of cytotoxic T cells by antiT3 linked to anti-target cell antibody. Nature. 1985;316:354-6. https://doi.org/ 10.1038/316354a0.

Posey AD, Schwab RD, Boesteanu AC, et al. Engineered CAR T cells targeting the Cancer-associated Tn-Glycoform of the membrane mucin MUC1 control adenocarcinoma. Immunity. 2016:44:1444-54. https://doi.org/10.1016/j. immuni.2016.05.014.

Rajasekaran A. Is prostate-specific membrane antigen a multifunctional protein? Cancer. 2015;121(3):403-12. https://doi.org/10.1002/cncr.29062.

Ravi R, Noonan KA, Pham V, et al. Bifunctional immune checkpoint-targeted antibody-ligand traps that simultaneously disable TGF $\beta$ enhance the efficacy of cancer immunotherapy. Nat Commun. 2018;9:741. https://doi.org/10.1038/ s41467-017-02696-6.

Rezvani $\mathrm{K}$, Rouce $\mathrm{RH}$. The application of natural killer cell immunotherapy for the treatment of cancer. Front Immunol. 2015;6:578.

Ross SL, Sherman M, McElroy PL, et al. Bispecific T cell engager (BiTE ${ }^{\oplus}$ ) antibody constructs can mediate bystander tumor cell killing. PLoS One. 2017;12: e0183390. https://doi.org/10.1371/journal.pone.0183390.

Rossi EA, Goldenberg DM, Cardillo TM, et al. Stably tethered multifunctional structures of defined composition made by the dock and lock method for use in cancer targeting. Proc Natl Acad Sci. 2006;103:6841-6. https://doi.org/ 10.1073/pnas.0600982103.

Schmohl JU, Felices M, Taras E, et al. Enhanced ADCC and NK cell activation of an anticarcinoma bispecific antibody by genetic insertion of a modified IL-15 cross-linker. Mol Ther. 2016;24:1312-22. https://doi.org/10.1038/mt.2016.88.

Sedykh SE, Prinz W, Buneva VN, Nevinsky GA. Bispecific antibodies: design, therapy, perspectives. Drug Des Devel Ther. 2018;12:195-208.

Segal DM, Weiner GJ, Weiner LM. Bispecific antibodies in cancer therapy. Curr Opin Immunol. 1999;11:558-62.

Seimetz D. Catumaxomab (Removab): the road from preclinical development to approval. J Immunother Conf. 2009;32:1008-9.

Seimetz D. Novel monoclonal antibodies for cancer treatment: the trifunctional an-tibody catumaxomab (Removab ${ }^{\circledR}$ ). J Cancer. 2011;2:309-16.

Shah MY, Ferrajoli A, Sood AK, et al. microRNA therapeutics in Cancer — an emerging concept. EBioMedicine. 2016;12:34-42.

Shinojima N, Tada K, Shiraishi S, et al. Prognostic value of epidermal growth factor receptor in patients with glioblastoma Multiforme. Cancer Res. 2003; 63:6962-70. https://doi.org/10.1158/0008-5472.can-04-1337.

Siegel R. Cancer Statistics, 2017. Ca Cancer J. 2017;67:7-30. https://doi.org/10. 3322/caac.21387.

Song H, Sgouros G. Radioimmunotherapy of solid tumors: searching for the right target. Curr Drug Deliv. 2011;8:26-44. https://doi.org/10.2174/ 156720111793663651

Spiess C, Zhai Q, Carter PJ. Alternative molecular formats and therapeutic applications for bispecific antibodies. Mol Immunol. 2015;67:95-106.

Staerz UD, Kanagawa O, Bevan MJ. Hybrid antibodies can target sites for attack by T cells. Nature. 1985;314:628-31. https://doi.org/10.1038/314628a0.
Tang Z, Du R, Jiang S, et al. Dual MET-EGFR combinatorial inhibition against T790M-EGFR-mediated erlotinib-resistant lung cancer. Br J Cancer. 2008;99: 911-22. https://doi.org/10.1038/sj.bjc.6604559.

Tay SS, Carol H, Biro M. TriKEs and BiKEs join CARs on the cancer immunotherapy highway. Hum Vaccines Immunother. 2016;12:2790-6.

Topp MS, Gökbuget N, Zugmaier G, et al. Phase II trial of the anti-CD19 bispecific T cell-engager blinatumomab shows hematologic and molecular remissions in patients with relapsed or refractory B-precursor acute lymphoblastic leukemia. J Clin Oncol. 2014;32:4134-40. https://doi.org/10.1200/JCO.2014.56.3247.

Vaishampayan U, Thakur A, Rathore R, et al. Phase i study of anti-CD3 x anti-her2 bispecific antibody in metastatic castrate resistant prostate cancer patients. Prostate Cancer. 2015;2015:285193. https://doi.org/10.1155/2015/285193.

van Rij CM, Frielink C, Goldenberg DM, et al. Pretargeted Radioimmunotherapy of prostate Cancer with an anti-TROP-2xAnti-HSG bispecific antibody and a (177)Lu-labeled peptide. Cancer Biother Radiopharm. 2014;29:323-9. https:// doi.org/10.1089/cbr.2014.1660

View FT, Gmbh FB, Biotech F, et al (2008) Phase II study with the trifunctional antibody Ertumaxomab to treat metastatic breast Cancer after progression on Trastuzumab therapy. ClinicaltrialsGov 1/1/2008-12/1/2009.

Wei $\mathrm{X}, \mathrm{Xu} \mathrm{H}$, Kufe D. Human mucin 1 oncoprotein represses transcription of the p53 tumor suppressor gene. Cancer Res. 2007;67:1853-8. https://doi.org/10. 1158/0008-5472.CAN-06-3063.

White CA, Berlfein JR, Grillo-Lopez AJ. Antibody-targeted immunotherapy for treatment of non-Hodgkin's lymphoma. Curr Pharm Biotechnol. 2000;1:30312. https://doi.org/10.2174/1389201003378889.

Yang F, Wen W, Qin W. Bispecific antibodies as a development platform for new concepts and treatment strategies. Int J Mol Sci. 2016;18:48. https://doi.org/ 10.3390/ijms18010048.

Yu S, Li A, Liu Q, et al. Recent advances of bispecific antibodies in solid tumors. J Hematol Oncol. 2017;10:155. https://doi.org/10.1186/s13045-017-0522-z.

Zeltsman M, Dozier J, McGee E, et al. CAR T-cell therapy for lung cancer and malignant pleural mesothelioma. Transl Res. 2017;187:1-10.

Zhang X, Yang Y, Fan D, Xiong D. The development of bispecific antibodies and their applications in tumor immune escape. Exp Hematol Oncol. 2017;6:12.

Zhukovsky EA, Morse RJ, Maus MV. Bispecific antibodies and CARs: generalized immunotherapeutics harnessing $T$ cell redirection. Curr Opin Immunol. 2016;40:24-35.

\section{Ready to submit your research? Choose BMC and benefit from:}

- fast, convenient online submission

- thorough peer review by experienced researchers in your field

- rapid publication on acceptance

- support for research data, including large and complex data types

- gold Open Access which fosters wider collaboration and increased citations

- maximum visibility for your research: over $100 \mathrm{M}$ website views per year

At BMC, research is always in progress.

Learn more biomedcentral.com/submissions 